\title{
Laminar Distribution of Neurons in Extrastriate Areas Projecting to Visual Areas V1 and V4 Correlates with the Hierarchical Rank and Indicates the Operation of a Distance Rule
}

\author{
Pascal Barone, Alexandre Batardiere, Kenneth Knoblauch, and Henry Kennedy \\ Cerveau et Vision, Institut National de la Santé, et de la Recherche Médicale U371, 69675 Bron Cedex, France
}

The directionality of corticocortical projections is classified as feedforward (going from a lower to higher hierarchical levels), feedback (interconnecting descending levels), and lateral (interconnecting equivalent levels). Directionality is determined by the combined criteria of the laminar patterns of the axon terminals as well as the cells of origins and has been used to construct models of the visual system, which reveals a strict hierarchical organization (Felleman and Van Essen, 1991; Hilgetag et al., 1996a). However, these models are indeterminate partly because we have no indication of the distance separating adjacent levels. Here we have attempted to determine a graded parameter describing the anatomical relationship of interconnected areas. We have investigated whether the precise percentage of labeled supragranular layer neurons (SLN\%) in each afferent area after injection in either

Rostral directed projections allow outflow of activity away from striate cortex [visual area V1] and are thought of as feedforward (FF) pathways. These projections originate largely from supragranular layers, target layer 4, and contrast with the reciprocal projections that originate in infragranular layers, terminate outside of layer 4, and are thought of as feedback (FB) pathways (Kuypers et al., 1965; Cragg, 1969; Spatz et al., 1970; Tigges et al., 1973, 1981; Lund et al., 1975; Kaas and Lin, 1977; Spatz, 1977; Wong-Riley, 1978; Van Essen and Zeki, 1978; Rockland and Pandya, 1979; Wall et al., 1982; Maunsell and Van Essen, 1983; Weller et al., 1984; Kennedy and Bullier, 1985; Weller and Kaas, 1985; Barbas, 1986, 1995; Andersen et al., 1990; Boussaoud et al., 1990; Morel and Bullier, 1990; Baizer et al., 1991; Colby and Duhamel, 1991; Webster et al., 1991, 1994; Sousa et al., 1991; Distler et al., 1993; Nakamura et al., 1993; Barone et al., 1995; Barbas and RempelClower, 1997; Felleman et al., 1997; Gattass et al., 1997).

The laminar patterns of corticocortical connections have been used to propose a hierarchical ranking of primate cortical areas in different sensory systems (Fitzpatrick and Imig, 1980; Friedman, 1983; Maunsell and Van Essen, 1983; Barbas, 1986; Pons and Kaas, 1986; Ungerleider and Desimone, 1986; Colby et al., 1988; Boussaoud et al., 1990; Van Essen et al., 1990; Felleman and Van Essen, 1991; Webster et al., 1991; Young, 1992; Distler et al., 1993; Webster et al., 1994; Hilgetag et al., 1996a; Barbas and Rempel-Clower, 1997; Felleman et al., 1997b; Kaas et al., 1999).

Received Nov. 15, 1999; revised Feb. 4, 2000; accepted Feb. 7, 2000.

This work was supported by the European Community, Quality of Life and Management of Living Resources (QLG3-1999-01064).

Correspondence should be addressed to Dr. Henry Kennedy, Cerveau et Vision Unité 371, Institut National de la Santé, et de la Recherche Médicale, 18 Avenue du Doyen Lépine, 69675 Bron Cedex, France. E-mail: kennedy@lyon151.inserm.fr. Copyright (C) 2000 Society for Neuroscience $0270-6474 / 00 / 203263-19 \$ 15.00 / 0$ visual areas V1 or V4 determines its hierarchical position in the Felleman and Van Essen (1991) model. This shows that pathway directionality in the Felleman and Van Essen model is characterized by a range of SLN\% values. The one exception is the projection of the frontal eye field to area V4, which resembles a feedforward projection. Individual areal differences in SLN\% values are highly significant, and the number of hierarchical steps separating a target area from a source area is found to be tightly correlated to SLN\%. The present results show that the hierarchical rank of each afferent area is reliably indicated by SLN\%, and therefore this constitutes a graded parameter that is related to hierarchical distance.

Key words: primate; monkey; extrastriate cortex; visual processing; hierarchical models; feedback

These models are constructed by categorizing connections between huge numbers of pairs of areas and ascribing each area to a hierarchical level in an optimal configuration. However, the number of possible configurations is enormous because of lack of criteria defining the distance separating levels (Hilgetag et al., 1996a,b). Here we have sought to overcome this problem by defining a single quantitative parameter of connectivity that will allocate areas to graded levels. Such a parameter could be provided by the proportion of supragranular layer neurons (SLN\%) participating in FF and FB pathways (Kennedy and Bullier, 1985; Barbas, 1986; Barone et al., 1995; Rockland, 1997; Batardière et al., 1998a).

Quantitative techniques were used to investigate SLN\% in individual areas projecting to visual areas V1 and V4 in macaque. Area V1, the primary visual area, is interconnected to areas in both the ventral and dorsal stream. Area V4 is a higher order visual area in the ventral stream and receives FF, lateral, and FB projections from higher order areas in the dorsal stream and ventral stream.

The SLN\% alone successf ully ranks cortical areas and is tightly correlated to the number of steps separating areas. The present findings, showing a graded parameter tightly correlated to hierarchical rank, indicate the existence of a hierarchical distance rule (Kennedy and Bullier, 1985; Rockland, 1997), which will allow an improved exploration of the organizational constraints of the interareal relationships in the visual system.

\section{MATERIALS AND METHODS}

Twenty-two retrograde tracer experiments were performed on 12 cynomolgus monkeys (Macaca fascicularis; Table 1).

Anesthesia and surgery. After premedication with atropine (1.25 mg, i.m.) and dexamethasone (4 mg, i.m.), monkeys were prepared for surgery under ketamine hydrochloride $(20 \mathrm{mg} / \mathrm{kg}$, i.m.) and chlorpromazine (2 $\mathrm{mg} / \mathrm{kg}$, i.m.). After intubation, anesthesia was continued with halothane 


\begin{tabular}{|c|c|c|c|c|c|c|c|c|c|c|c|c|c|c|c|c|}
\hline \multirow[b]{2}{*}{ Case } & \multirow[b]{2}{*}{ Plane } & \multicolumn{3}{|l|}{ V1 } & \multicolumn{3}{|l|}{$\mathrm{V} 2$} & \multicolumn{3}{|l|}{ V3 } & \multicolumn{3}{|l|}{ V4 } & \multicolumn{3}{|l|}{ MT } \\
\hline & & $\begin{array}{l}\text { SNL } \\
\%\end{array}$ & $\begin{array}{l}\mathrm{N} \\
\mathrm{Nr}\end{array}$ & $\begin{array}{l}\mathrm{N} \\
\text { Sct }\end{array}$ & $\begin{array}{l}\text { SNL } \\
\%\end{array}$ & $\begin{array}{l}\mathrm{N} \\
\mathrm{Nr}\end{array}$ & $\begin{array}{l}\mathrm{N} \\
\text { Sct }\end{array}$ & $\begin{array}{l}\text { SNL } \\
\%\end{array}$ & $\begin{array}{l}\mathrm{N} \\
\mathrm{Nr}\end{array}$ & $\begin{array}{l}\mathrm{N} \\
\text { Sct }\end{array}$ & $\begin{array}{l}\text { SNL } \\
\%\end{array}$ & $\begin{array}{l}\mathrm{N} \\
\mathrm{Nr}\end{array}$ & $\begin{array}{l}\mathrm{N} \\
\text { Sct }\end{array}$ & $\begin{array}{l}\text { SNL } \\
\%\end{array}$ & $\begin{array}{l}\mathrm{N} \\
\mathrm{Nr}\end{array}$ & $\begin{array}{l}\mathrm{N} \\
\text { Sct }\end{array}$ \\
\hline \multicolumn{17}{|l|}{ V1 INJECTIONS } \\
\hline BKO18/LH FsB & $\mathrm{H}$ & & & & 53,00 & 3641 & 7 & & & & & & & & & \\
\hline BKO15 & $\mathrm{H}$ & & & & 44,00 & 1949 & 7 & & & & & & & & & \\
\hline M21 & $\mathrm{H}$ & & & & 55,26 & 4256 & 12 & & & & & & & & & \\
\hline M38 & $\mathrm{H}$ & & & & & & & & & & & & & 2,50 & 1891 & 19 \\
\hline M37/RH FsB & $\mathrm{H}$ & & & & 51,88 & 3248 & 12 & & & & & & & 4,60 & 1070 & 21 \\
\hline M37/RH DY & $\mathrm{H}$ & & & & 53,46 & 4027 & 15 & & & & & & & 5,50 & 1951 & 21 \\
\hline M37/LH FsB & $\mathrm{H}$ & & & & 53,70 & 16465 & 32 & & & & & & & 7,00 & 890 & 24 \\
\hline M37/LH DY & $\mathrm{H}$ & & & & 43,20 & 15977 & 29 & & & & & & & 5,30 & 1446 & 24 \\
\hline M71 LH DY & $P$ & 65,39 & 10508 & 2 & 39,97 & 2372 & 16 & 11,96 & 811 & 21 & 10,02 & 1028 & 25 & 5,41 & 296 & 16 \\
\hline M71 LH FsB & $\mathrm{P}$ & 68,02 & 6016 & 2 & 50,13 & 1971 & 16 & 8,26 & 484 & 21 & 7,09 & 268 & 25 & 5,37 & 205 & 17 \\
\hline M71 RH DY & $\mathrm{P}$ & 54,16 & 4586 & 2 & 34,72 & 5346 & 21 & 7,21 & 874 & 23 & 12,01 & 1091 & 21 & 5,26 & 342 & 20 \\
\hline M71 RH FsB & $P$ & 55,72 & 12686 & 4 & 43,47 & 8574 & 21 & 6,74 & 1306 & 23 & 14,24 & 864 & 21 & 6,25 & 528 & 20 \\
\hline M56 RHFsB* & $\mathrm{P}$ & & & & & & & & & & & & & & & \\
\hline M56 RHDY* & $\mathrm{P}$ & & & & & & & & & & & & & & & \\
\hline M73 LH* & $\mathrm{P}$ & & & & & & & & & & & & & & & \\
\hline Mean & & 60,82 & & & 47,53 & & & 8,54 & & & 10,84 & & & 5,24 & & \\
\hline SE & & 3,45 & & & 2,04 & & & 1,18 & & & 1,52 & & & 0,41 & & \\
\hline \multicolumn{17}{|l|}{ V4 INJECTIONS } \\
\hline BB187 FsB & $\mathrm{H}$ & 100 & 46 & 14 & 94,23 & 3724 & 35 & 58,37 & 1201 & 21 & 63,80 & 3655 & 2 & 46,67 & 1395 & 12 \\
\hline BB187 DY & $\mathrm{H}$ & 100 & 10 & 14 & 98,87 & 4591 & 33 & 67,21 & 2458 & 21 & 70,42 & 5396 & 2 & 55,10 & 1579 & 12 \\
\hline BB119 FsB & $\mathrm{H}$ & 100 & 9 & 13 & 88,77 & 3162 & 21 & 51,73 & 2111 & 15 & & & & 47,12 & 832 & 19 \\
\hline BB119 DY & $\mathrm{H}$ & 100 & 2 & 13 & 84,62 & 3362 & 21 & 47,03 & 1916 & 15 & & & & 43,37 & 618 & 19 \\
\hline BB135 & $\mathrm{H}$ & 100 & 1 & 14 & 96,46 & 3620 & 14 & 67,84 & 768 & 6 & 66,99 & 9112 & 2 & 25,65 & 5610 & 19 \\
\hline M72 FsB & $\mathrm{H}$ & 100 & 7 & 30 & 94,09 & 8454 & 30 & 52,05 & 3218 & 13 & & & & 57,37 & 1283 & 12 \\
\hline M72 DY & $\mathrm{H}$ & & 0 & 30 & 96,71 & 5136 & 30 & 74,02 & 3603 & 13 & 55,87 & 11542 & 2 & 54,77 & 953 & 10 \\
\hline Mean & & 100,00 & & & 93,39 & & & 59,75 & & & 64,27 & & & 47,15 & & \\
\hline SE & & 0,00 & & & 1,89 & & & 3,82 & & & 3,11 & & & 4,09 & & \\
\hline
\end{tabular}

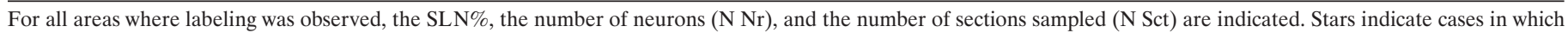

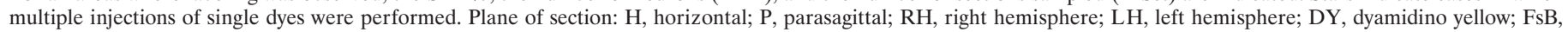
fast blue.

in a $\mathrm{N}_{2} \mathrm{O} / \mathrm{O}_{2}(70: 30)$ mixture. Heart rate was monitored, and artificial respiration was adjusted to maintain the end-tidal $\mathrm{CO}_{2}$ at $4.5-6 \%$. The rectal temperature was maintained at $37^{\circ} \mathrm{C}$. All the procedures used follow the National and European regulations concerning animal experiments and have been approved by the authorized national and veterinary agencies.

Injection of retrograde tracers. Single injections of retrograde fluorescent tracers [fast blue (FsB) and diamidino yellow (DY), 3\% in $\mathrm{H}_{2} \mathrm{O}$ ] were made by means of Hamilton syringes. In three cases [M56 right hemisphere (RH) FsB, M56 RHDY, M73 left hemisphere (LH)] multiple injections were made in area V1 (Table 1). In the remaining 19 cases, injections of tracers spanned $1-5 \mathrm{~mm}$ and were made in a stereotypical manner. Injections were made in area V4 according to the definition of Desimone and Ungerleider (1986). They were centered on the prelunate gyrus between the lunate sulcus, the infero-occipital sulcus, and the superior temporal sulcus in area V4 containing the representation of the central visual field (Maguire and Baizer, 1984; Gattass et al., 1988). Injections aimed at area V1 were made on the operculum in area V1 containing the representation of the central visual field (Hubel and Wiesel 1974; Van Essen et al., 1984). When an FsB and a DY injection were made side-by-side, they were separated by $\sim 3 \mathrm{~mm}$. Elsewhere we have characterized the uptake zone of FsB and DY tracers (Bullier et al., 1984; Kennedy and Bullier, 1985). Examination of sections at regular intervals throughout the injection site makes it possible to determine those restricted to gray matter. All the injections but one was restricted to the cortical gray matter. The one injection that involved the white matter (BB135) returned similar values to the other injections, which confirms previous results (Barone et al., 1995; Batardière et al., 1998a). After injections, bone flaps were closed, and the scalp was stitched back into position.
Histological processing. After a survival period of 10-13 d, animals were deeply anesthetized before being perfused transcardially with 200 $\mathrm{ml}$ of $2.7 \%$ saline, $1-31$ of $8 \%$ paraformaldehyde $/ 0.5 \%$ glutaraldehyde mixture in phosphate buffer $(0.1 \mathrm{M}, \mathrm{pH} 7.4), 0.51$ of $10 \%$ sucrose, 0.51 of $20 \%$ sucrose, and 11 of $30 \%$ sucrose in phosphate buffer $(0.1 \mathrm{M}, \mathrm{pH} 7.4)$. Brains were immediately removed, blocked, and horizontal or parasagittal sections (Table 1) were cut on a freezing microtome (section thickness, $40 \mu \mathrm{m}$ ). One section in three was mounted in saline onto gelatinized slides. Sections at regular intervals were reacted for cytochrome oxidase (Silverman and Tootell, 1987) and acetylcholinesterase activity (Hardy et al., 1976; Mesulam and Geula, 1994).

Examination of material. Sections were observed in UV light with oil-immersion objectives using a Leitz fluorescent microscope equipped with a D-filter set $(355-425 \mathrm{~nm})$. The properties and description of neurons labeled with FsB and DY are described by Keizer et al. (1983). Neurons labeled by DY exhibit a yellow nucleus, whereas neurons labeled by FsB exhibit a blue coloration in their cytoplasm. Labeled cells are observed in both infragranular and supragranular layers. An $x-y$ plotter electronically coupled to the microscope stage was used to trace out sections and to record the position of labeled neurons. After observation, sections were counterstained with cresyl violet and projected onto charts of labeled neurons to relate the position of labeled neurons to histological borders.

Areal and laminar distribution of labeled neurons. The areal extent of a population of retrogradely labeled neurons in a cortical area after injection in the target area is referred to as a projection zone (Fig. $1 A-C$ ). The proportion of supragranular layer neurons falls off from a peak in the center of the projection zone to minimal values in the periphery (Fig. 1D) (Meissirel et al., 1991; Barone et al., 1995; Batardière et al., 1998a). This, coupled with the curvature of the cortex, necessitates estimating 


\begin{tabular}{|c|c|c|c|c|c|c|c|c|c|c|c|c|c|c|c|c|c|}
\hline \multicolumn{3}{|l|}{ FST } & \multicolumn{3}{|l|}{$\underline{\text { LIP }}$} & \multicolumn{3}{|l|}{ TEO } & \multicolumn{3}{|l|}{ TE } & \multicolumn{3}{|c|}{ TH-TF } & \multicolumn{3}{|l|}{ FEF } \\
\hline $\begin{array}{l}\text { SNL } \\
\%\end{array}$ & $\begin{array}{l}\mathrm{N} \\
\mathrm{Nr}\end{array}$ & $\begin{array}{l}\mathrm{N} \\
\text { Sct }\end{array}$ & $\begin{array}{l}\text { SNL } \\
\%\end{array}$ & $\begin{array}{l}\mathrm{N} \\
\mathrm{Nr}\end{array}$ & $\begin{array}{l}\mathrm{N} \\
\text { Sct }\end{array}$ & $\begin{array}{l}\text { SNL } \\
\%\end{array}$ & $\begin{array}{l}\mathrm{N} \\
\mathrm{Nr}\end{array}$ & $\begin{array}{l}\mathrm{N} \\
\text { Sct }\end{array}$ & $\begin{array}{l}\text { SNL } \\
\%\end{array}$ & $\begin{array}{l}\mathrm{N} \\
\mathrm{Nr}\end{array}$ & $\begin{array}{l}\mathrm{N} \\
\text { Sct }\end{array}$ & $\begin{array}{l}\text { SNL } \\
\%\end{array}$ & $\begin{array}{l}\mathrm{N} \\
\mathrm{Nr}\end{array}$ & $\begin{array}{l}\mathrm{N} \\
\text { Sct }\end{array}$ & $\begin{array}{l}\text { SNL } \\
\%\end{array}$ & $\begin{array}{l}\mathrm{N} \\
\mathrm{Nr}\end{array}$ & $\begin{array}{l}\mathrm{N} \\
\text { Sct }\end{array}$ \\
\hline
\end{tabular}

\begin{tabular}{|c|c|c|c|c|c|c|c|c|c|c|c|c|c|c|c|c|c|}
\hline 0,00 & 66 & 17 & 11,11 & 9 & 25 & 0,00 & 53 & 12 & 0,00 & 61 & 12 & 0,00 & 5 & 7 & & & \\
\hline 0,00 & 59 & 17 & 0,00 & 6 & 25 & 1,45 & 69 & 12 & 0,00 & 44 & 12 & 0,00 & 4 & 7 & & & \\
\hline 0,00 & 100 & 21 & 0,00 & 2 & 20 & 0,00 & 65 & 16 & 0,00 & 74 & 21 & 0,00 & 6 & 9 & & 0 & \\
\hline \multirow[t]{4}{*}{0,00} & 189 & 21 & 0,00 & 7 & 20 & 0,30 & 329 & 16 & 0,25 & 404 & 21 & 0,00 & 34 & 9 & & 0 & \\
\hline & & & 0,00 & 9 & 42 & & & & & & & & & & & & \\
\hline & & & 3,57 & 28 & 42 & & & & & & & & & & & & \\
\hline & & & 0,00 & 14 & 4 & & & & & & & & & & 0,00 & 6 & \\
\hline 0,00 & & & 2,10 & & & 0,44 & & & 0,06 & & & 0,00 & & & 0,00 & & \\
\hline 0,00 & & & 1,58 & & & 0,34 & & & 0,06 & & & 0,00 & & & & & \\
\hline 4,95 & 222 & 19 & 22,22 & 99 & 15 & 43,27 & 2281 & 13 & 35,94 & 2485 & 17 & 0,00 & 600 & 11 & 71,79 & 39 & 15 \\
\hline 2,08 & 144 & 19 & 22,55 & 102 & 15 & 30,65 & 1589 & 13 & 32,16 & 1480 & 17 & 0,00 & 259 & 11 & 95,65 & 23 & 15 \\
\hline 44,76 & 286 & 11 & 59,76 & 410 & 21 & 57,06 & 3214 & 19 & 31,54 & 1379 & 13 & 4,77 & 818 & 6 & 69,62 & 339 & 23 \\
\hline 9,46 & 74 & 11 & 25,13 & 593 & 21 & 39,52 & 2735 & 19 & 14,04 & 413 & 13 & 0,00 & 95 & 6 & 53,33 & 105 & 23 \\
\hline 14,8 & 304 & 12 & 25,26 & 1461 & 26 & 47,06 & 5861 & 16 & 8,11 & 2477 & 16 & 0,59 & 850 & 13 & 68,14 & 521 & 17 \\
\hline 12,86 & 933 & 26 & 23,56 & 191 & 14 & 36,45 & 2524 & 9 & 30,45 & 3327 & 14 & 0,38 & 788 & 12 & 76,34 & 93 & 11 \\
\hline 8,42 & 463 & 24 & 9,90 & 202 & 14 & 24,44 & 753 & 9 & 28,00 & 1193 & 14 & 0,00 & 415 & 12 & 73,02 & 63 & 11 \\
\hline 13,90 & & & 26,91 & & & 39,78 & & & 25,75 & & & 0,82 & & & 72,56 & & \\
\hline 5,40 & & & 5,83 & & & 4,06 & & & 3,95 & & & 0,66 & & & 4,75 & & \\
\hline
\end{tabular}

the relative proportions of large numbers of labeled neurons in supragranular and infragranular layers by counting neurons at regular intervals throughout each projection zone in each of the visual areas studied (Barone et al., 1995; Batardière et al., 1998a). The laminar distribution for each projection zone is expressed as the SLN\% with respect to the overall population of infragranular and supragranular labeled neurons.

Criteria for the location of cortical areas. Injections of tracers in areas $\mathrm{V} 1$ and V4 leads to dense labeling of an extensive region of extrastriate cortex in the parietal and temporal regions (Zeki, 1978; Maunsell and Van Essen, 1983; Kennedy and Bullier, 1985; Yukie and Iwai, 1985; Perkel et al., 1986; Tanaka et al., 1990; Felleman and Van Essen, 1991; Baizer et al., 1991; Krubitzer and Kaas, 1993; Shipp and Zeki, 1995). Label in extrastriate cortex was observed in different known visual areas: V1, V2, V3, V3A, V4, middle temporal area (MT), fundus superior temporal area (FST), temporal occipital area (TEO), temporal area (TE), lateral intraparietal area (LIP), and TH-TF, as well as frontal eye field (FEF) (Fig. 2). Multiple criteria were used to allocate labeled neurons to one of these 12 areas. It was important to optimize the criteria used to distinguish different cortical areas to be able to count neurons throughout a maximum extent of the projection zones in individual areas. Some architectonic limits were obtained using Nissl staining, cytochrome oxidase, or acetylcholinesterase histochemistry, but a major criteria is the pattern of labeling itself. Because the injection sites involved cortex containing the representation of the central visual field, cortical areas that share borders where the far periphery of the visual field is represented show a discontinuous pattern of labeling. This gap in the labeling provides an important indication of the limits of the cortical area (Fig. 3).

Area V1 is located in the posterior part of the brain, and the limits with area V2 are easily identified using cresyl violet staining. The location of extrastriate areas is shown in Figure 2. Area V2 is located in the posterior bank of the lunate sulcus (Van Essen and Zeki, 1978; Gattass et al., 1981) where it can be identified with cytochrome oxidase and acetylcholinesterase histochemistry (Tootell et al., 1983; Livingstone and Hubel, 1984; Barone et al., 1994).

Area V3 is located laterally in the fundus of the lunate sulcus and more medially in the posterior part of the anectant gyrus, whereas area V3A is located anterior to V3 in the anterior bank of the lunate sulcus (LS) (Zeki, 1971, 1978; Van Essen et al., 1986; Gattass et al., 1988; Felleman et al., 1997b). Mediodorsal injections in the perifoveal representation of area V1 led to restricted labeling in the anectant gyrus corresponding to area V3, as defined by Felleman et al. (1997b). This region corresponds to a subregion of the dorsomedial visual area (DM) following the definition of Beck and Kaas (1999). Labeling in area V3 is separated from labeling in area V2, which is located more medially. After injection in area V1 no labeled cells are found in area V3A in the anterior bank of the LS in agreement with previous observations (Van Essen et al., 1986; Felleman et al., 1997b). After injections in area V4, labeling was restricted to area V3A. In most cases there is a gap between the labeling in area $\mathrm{V} 2$ and $\mathrm{V} 3 \mathrm{~A}$, and going from area $\mathrm{V} 2$ to $\mathrm{V} 3 \mathrm{~A}$, there is a distinct increase in the density of labeling in the infragranular layers of area V3A (Fig. 3A).

Area MT is located in the posterior bank of the superior temporal sulcus (STS) and stretches from the fundus to approximately halfway up the sulcus (Zeki, 1974; Desimone and Gross, 1979; Van Essen et al., 1981; Maunsell and Van Essen, 1983; Ungerleider and Desimone, 1986). After V1 injection, the labeling in the dorsal part of the STS is well isolated from the labeling in the prelunate gyrus. This gap is more or less pronounced in cases of V4 injections, which induce a strong labeling in the adjacent area V4t (Fig. 3) (Desimone and Ungerleider, 1986; Gattass et al., 1988; Felleman and Van Essen, 1991).

After V1 and V4 injections, labeling is found in the visual motion area FST in the floor of the STS, which is anterior and ventral to area MT 
M71 RH-FB/ Area V2

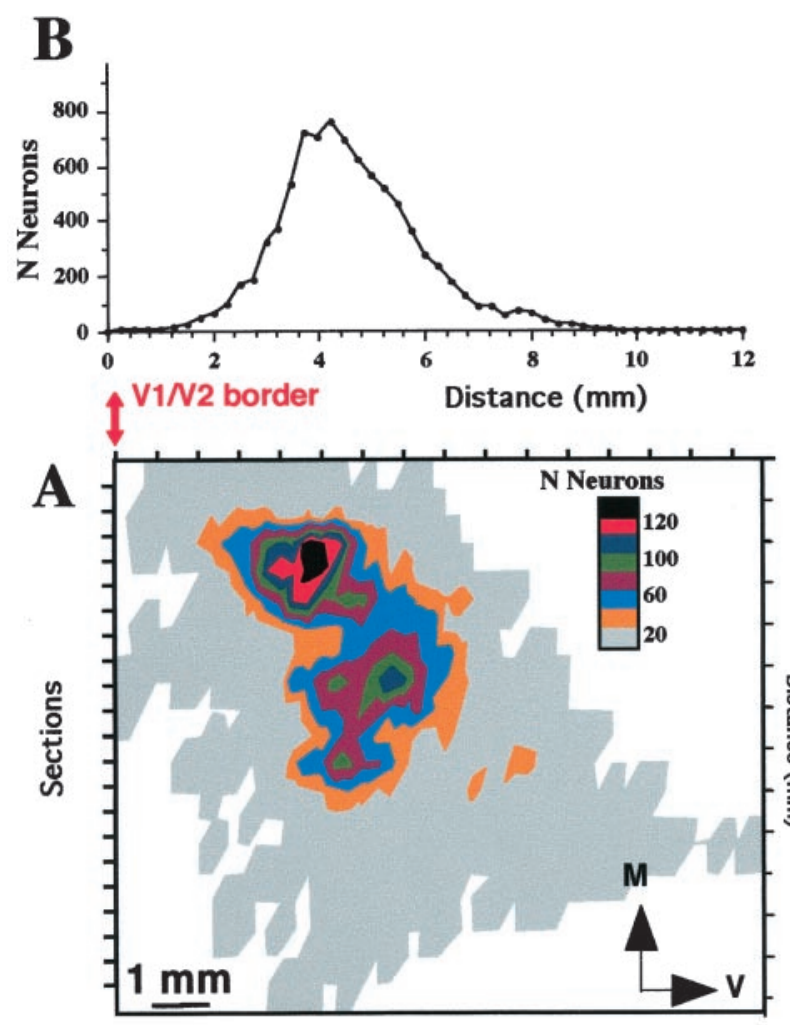

BB135-FB/ Area MT
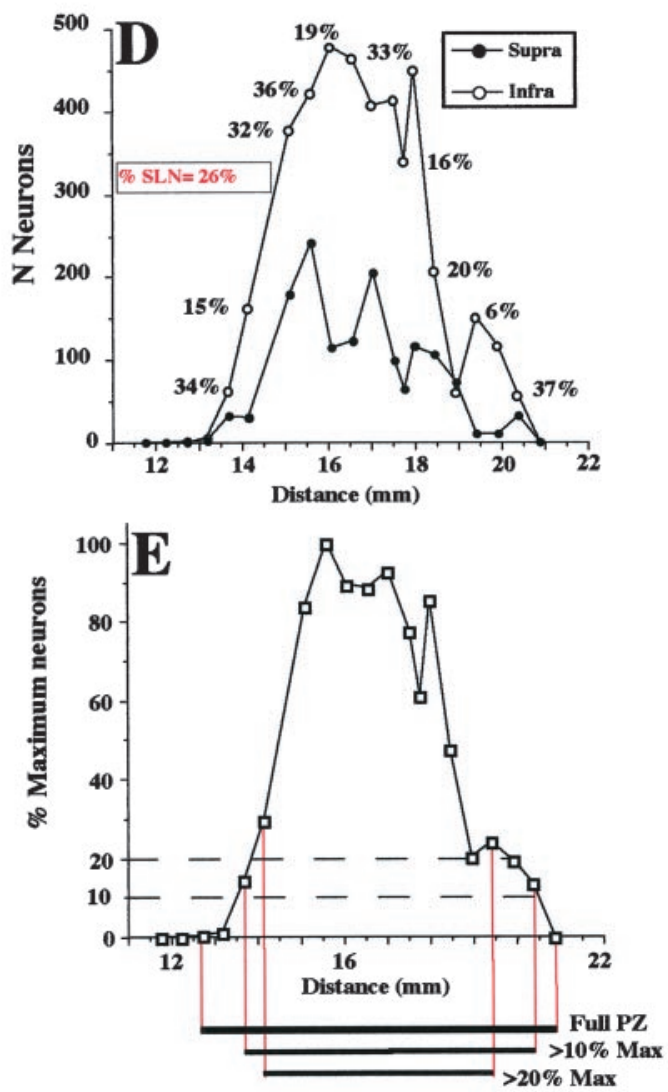

Figure 1. A-C, Analysis of a projection zone in area V2 after injection in area V1. $A$, Two-dimensional reconstruction of the projection zone. Area V1-V2 border is to the left (arrow), and fundus of the lunate sulcus is to the right. B, Density profile in the dorsoventral direction, showing the number of neurons counted at regular intervals on parasagittal sections. Counts are aligned on the V1-V2 border indicated by an arrow ( 0 on the $x$-axis, 12 is toward the fundus of the LS). $C$, Density profile in the lateromedial direction showing numbers of labeled neurons per section. 0 is an arbitrary start point that corresponds to absence of labeling. $D, E$, Projecting zone in area MT after an injection in area V4. $D$, Density profile of the labeled neurons in supragranular and infragranular layers. The SLN\% values are indicated and show that on individual sections SLN\% values can range in the center of the projection zone from $16-36 \%$. E shows the effects of 10 and $20 \%$ of maximum neuron thresholds on the dimensions of the projection zone (PZ). When these thresholds are applied, the size of the projections zone is reduced by 22 and $39 \%$, respectively, whereas the SLN values change for $<0.3 \%$.

(Seltzer and Pandya, 1978; Desimone and Ungerleider, 1986; Ungerleider and Desimone, 1986; Boussaoud et al., 1990).

Labeling in the posterior and lateral bank of the intraparietal cortex is isolated from labeling in other areas and corresponds to the LIP (Andersen et al., 1990; Blatt et al., 1990; Boussaoud et al., 1990; Baizer et al., 1991; Colby and Duhamel, 1991; Shipp and Zeki, 1995; Colby et al., 1996).

The major input to area V4 from higher order areas is from the visual areas in the temporal lobe. Only scattered labeled cells were observed in the temporal lobe after injection in V1. Area TEO is located on the temporal lobe between the inferior occipital sulcus and the superior temporal sulcus (Iwai and Mishkin, 1969; Baizer et al., 1991; Boussaoud et al., 1991; Distler et al., 1993). Labeling is discontinuous between V4 and TEO. Anterior and ventral to TEO in the inferior temporal cortex is the temporal area TE (see also Van Essen et al., 1990; Webster et al., 1991, 1994).

In the ventral region of the temporal lobe in the parahippocampal cortex is the lateral cortical area TF and the medial area TH. These cortical areas are located medial to the rhinal fissure and posterior to the perirhinal cortex (Amaral et al., 1987; Suzuki and Amaral, 1994a,b; Suzuki, 1996). Anteriorly and medially, labeling in TF/TH shows a gap with labeling in the ventral part of areas TE at the level of the rhinal fissure (Fig. 3C).

In the frontal cortex, labeled neurons are found systematically in the anterior bank of the arcuate sulcus, which is known to house the FEF (area 8) (Bruce and Goldberg, 1985; Huerta et al., 1987; Stanton et al., 1989).
Statistical tests. A multinomial ANOVA (Woodward et al., 1990) was used to test the hypothesis that the SLN\% is equal across visual areas. Infragranular and supragranular layers were treated as within-subject factors in the analysis. By testing proportions, the problem of the variation in total number of cells is removed. The analysis does, however, incorporate the total numbers of labeled cells in the estimates of variance for each proportion, so that proportions based on small total numbers have less precision than those based on larger numbers. When a significant difference between areas was observed, the multinomial ANOVA allows us to do planned comparisons to identify the areas that violate the null hypothesis. To test the relationship between SLN\% and the number of levels that separate two interconnected areas, we used the nonparametric Spearman rank correlation test.

\section{RESULTS}

Injections of areas V1 and V4 were performed in a stereotypical manner, they were large and spanned $1-5 \mathrm{~mm}$, a method that reduces the possibility that patchiness of the target area (DeYoe et al., 1994) will influence the SLN values obtained (Scannell et al., 2000). Injections in areas V1 and V4 led to dense retrograde labeling throughout a large extent of extrastriate cortex. The criteria used to allocate neurons to individual areas is given in Materials and Methods. Retrogradely labeled neurons in the thalamus after injections in areas V1 and V4 are confined to 
$\mathbf{5 0}$

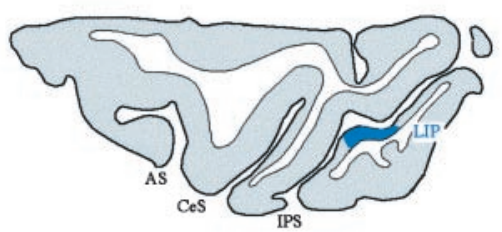

70

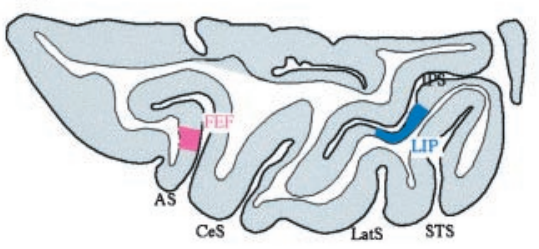

90
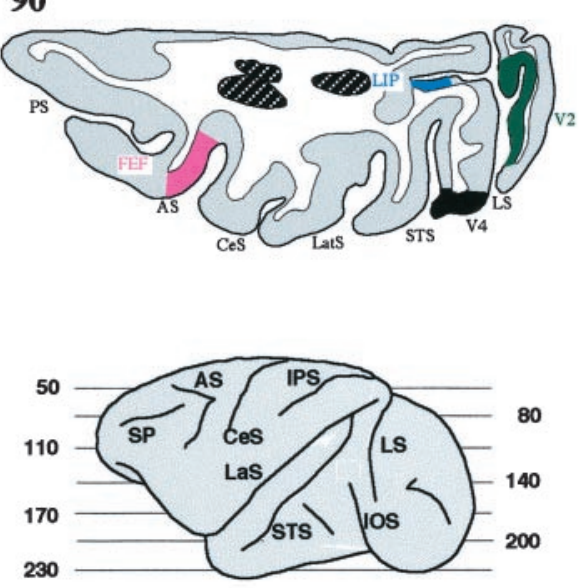

110

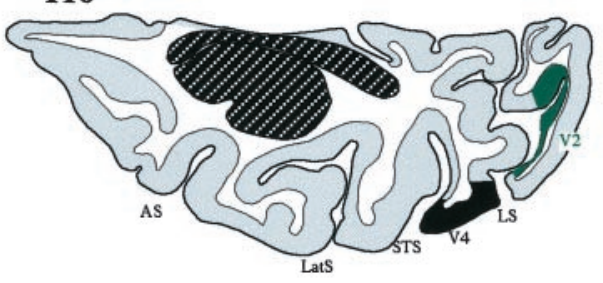

130

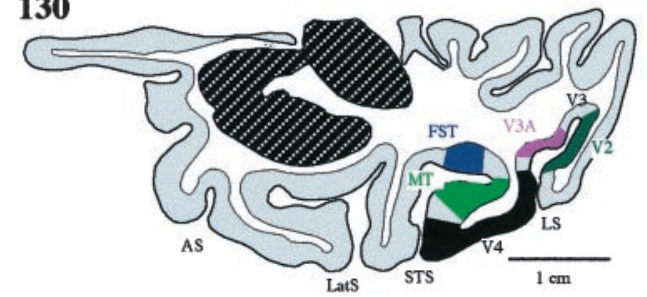

150
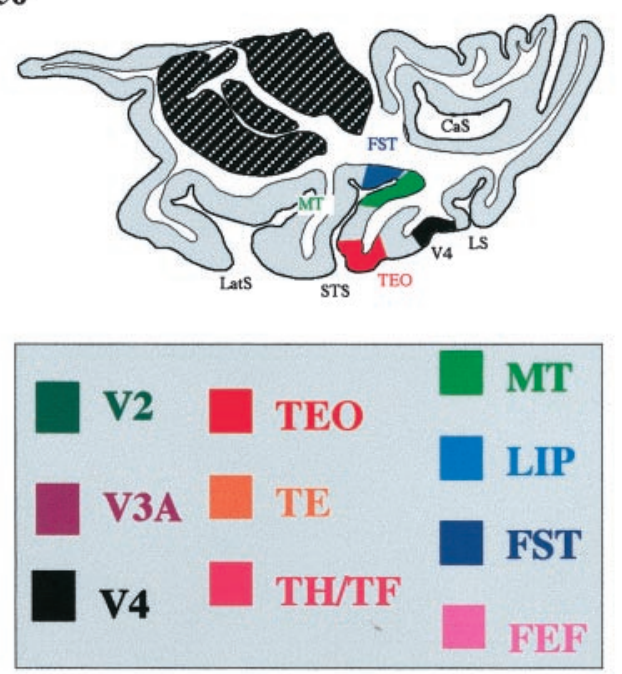

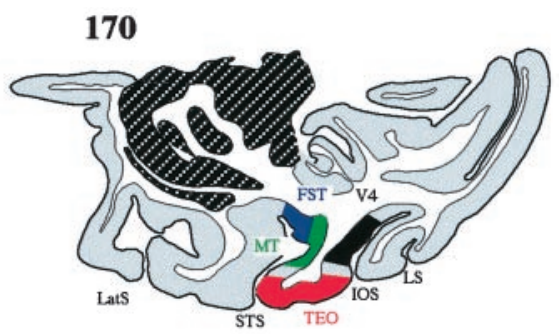

190

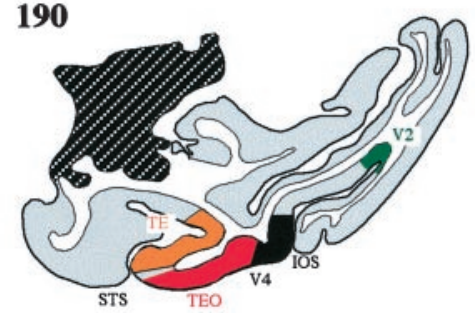

210

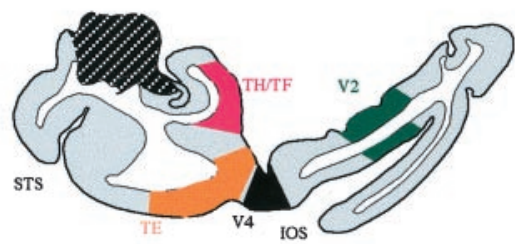

230

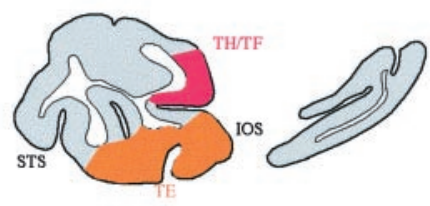

Figure 2. Horizontal sections showing the location of labeling in the extrastriate and frontal areas examined in this study. All cortical areas but one (V3A) that project to area V4 also project to area V1. MT, Middle temporal area; $T E O$, temporal occipital area; TE, temporal area; $F S T$, fundus superior temporal area; $L I P$, lateral intraparietal area; $F E F$, frontal eye field; $L S$, lunate sulcus; POS, posterior occipital sulcus; STS, superior temporal sulcus; IOS, inferior occipital sulcus; $A S$, arcuate sulcus; $L a t S$, lateral sulcus; $C e S$, central sulcus; $P S$, principal sulcus; $I P S$, intraparietal sulcus; $C a S$, calcarine sulcus.

the relevant thalamic nuclei, in the lateral geniculate nucleus and the lateral pulvinar (Kennedy and Bullier 1985; Tanaka et al., 1990; Baleydier and Morel, 1992; Shipp and Zeki, 1995).

\section{Laminar distributions: fluctuation within the projection zone}

For each cortical area and in each animal, numbers of neurons in each laminar compartment were computed for one in every three or four sections (see Materials and Methods). The regional extent of the area that contains the labeled neurons is referred as the projection zone. A representative two-dimensional reconstruction of a projection zone is shown in Figure $1 A$, which illustrates the spatial distribution of labeling in area V2 after injection in area V1. At the periphery of the projecting zone, the number of labeled neurons is low and increases to reach a maximum at the center. Density profiles (Fig. $1 B, C$ ) provide a one-dimensional reconstruction of the projection zone and constitute a graphic representation of labeling, which make it possible to ensure that the appropriate sampling frequency and choice of sections have been used for each projection zone in each area. Density profiles for all projection zones were prepared that show numbers of neurons per slide going through the projection zone where the $x$-axis is distance in millimeters. Here and elsewhere (Barone et al., 1995; Batardière et al., 1998a) SLN\% is found to vary throughout the projection zone, including the core regions (Fig. 1D). A major factor that contributes to this phenomena is the curvature of the cortex with respect to the plane of section, which results in single sections providing an uneven sampling of individual layers. Calculating SLN\% at regular intervals across the projection serves to overcome this problem of cortical curvature. A representative density profile for each cortical area is shown in the right-hand side of Figures 4-9. Examination of the density profiles show that peak percentages are located toward the centers of projection zones and fall off to zero in the periphery (Figs. 4-8). The density profiles illustrate the problems associated with estimating the laminar distribution. For example, because of cortical curvature and changing plane of section, peak levels of supragranular and infragranular layers frequently do not coincide (e.g., Fig. 4, top left-hand density curve; Fig. 6, three of the four density curves for MT and for LIP). 
Figure 3. Laminar pattern of retrogradely labeled cells in adjacent cortical areas projecting to $\mathrm{V} 4$. $A$, The labeling in area V3A in the anterior bank of the LS can be distinguished from the labeling in V2 in the posterior bank of the LS by an increase of density in infragranular layers. Labeling in V3A is separate from the labeling in $\mathrm{V} 2$ because $\mathrm{V} 3$ shows weak or no projection to area V4. Labeling is isolated from the intrinsic labeling in V4 (indicated in gray) surrounding the injection sites (shown in black). Very few labeled cells are observed in area V1. B, Despite the fact that V4t and V5 share a border with a central field representation, labeling in these two areas was largely discontinuous as shown in this example (see Results). $C$, Discontinuity of labeling between the areas TE and TH-TF. Individual values of SLN\% calculated in regions delimited by arrows are indicated. Scale bars, $1 \mathrm{~mm}$.

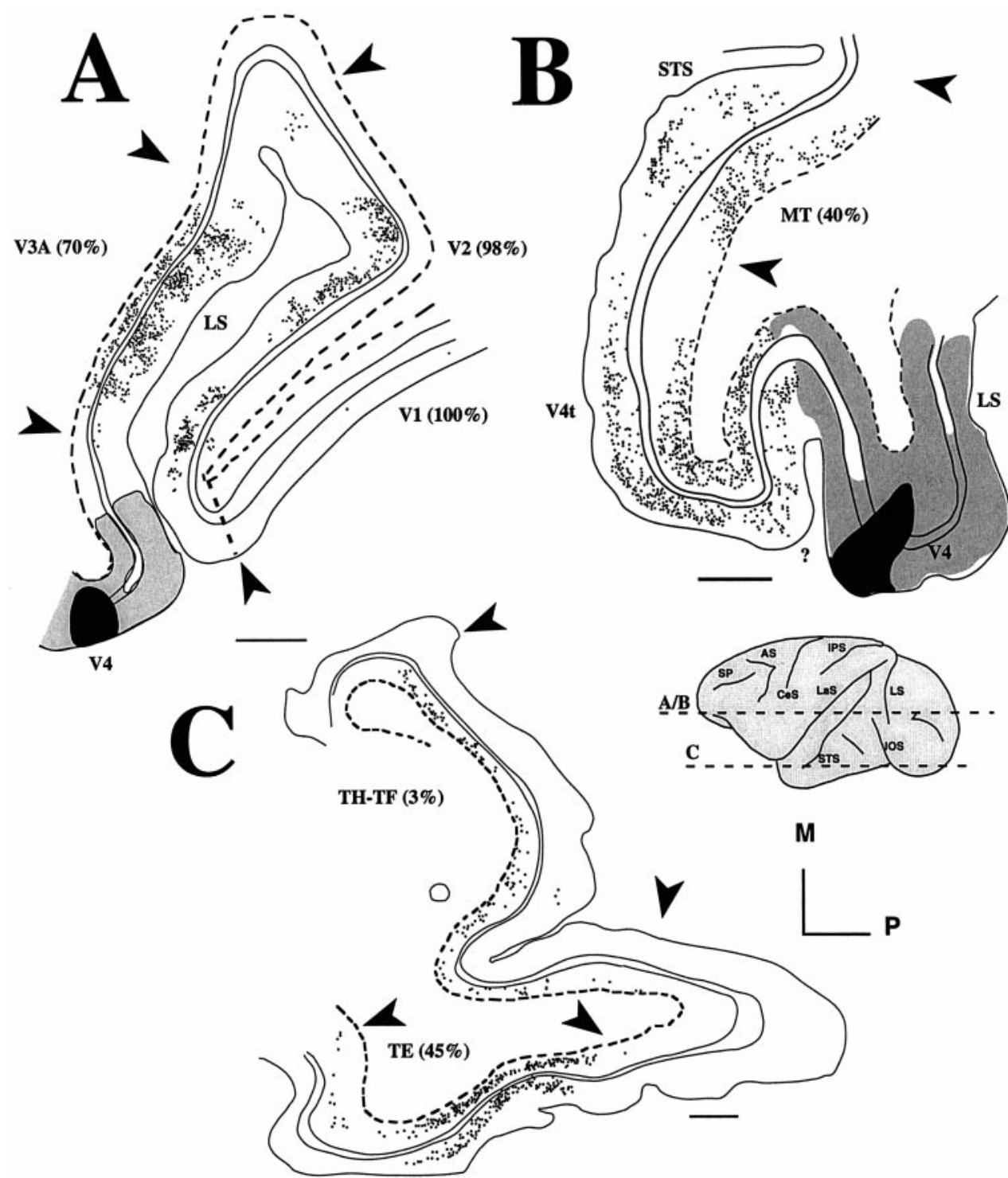

Changes of plane of section of the cortical compartments also contribute to the variability of the number of neurons in each compartment even on neighboring sections (Batardière et al., 1998a). For example, in area V2 after injection in area V1 in the case of M71 LH FsB (Fig. 4, top) individual sections in the central region show a SLN\% range of $12-67 \%$. When the SLN\% is calculated throughout the projection zone, this injection returns a value of $50 \%$. Similar results are obtained after the V4 injections (Fig. 1D). For example, in BB119 the DY injection in area V4 (Fig. 4, bottom) leads to SLN\% in the central region of the projection zone of area $\mathrm{V} 3 \mathrm{~A}$ ranging between 34 and $64 \%$, whereas global values are $47 \%$. These observations again demonstrate the necessity to calculate global values of SLN\% throughout the projection zone to characterize the laminar distribution for a single injection (Kennedy et al., 1989; Meissirel et al., 1991; Barone et al., 1995; Batardière et al., 1998a).

Variation of the SLN\% across the projection zones could also mean that individual projection zones are hybrid for FF, FB, and lateral connections, as suggested elsewhere (Ungerleider and Desimone, 1986; Andersen et al., 1990). The possibility that projection zones are hybrid reinforces the need to calculate the laminar distribution of connectivity after large injections and computing SLN\% throughout the whole of the projection zone, thereby obtaining a global value for the connection being studied.

Analysis of the effect of threshold values shows that projection zone structures are reasonably robust. Figure $1 E$ shows the effect of taking a 10 or $20 \%$ threshold of the maximum labeling on an individual projection zone in area MT after injection in area V4. Collectively, a $10 \%$ cutoff for all projection zones pooled leads to a $3 \%$ drop in the numbers of neurons counted and $0.4 \%$ change in SLN\% value.

Examination of the density profiles for projections zones in individual cortical areas makes it possible to select representative charts of labeled neurons from the center of the projection zones (Figs. 4-8, left-hand side).

\section{Reliability of allocation of labeled neurons to individual cortical areas}

In the present study we have used the pattern of labeling as a major criteria for the allocation of neurons to individual areas. Here we shall examine the reliability of this method. Injections of 


\section{AREA V2}

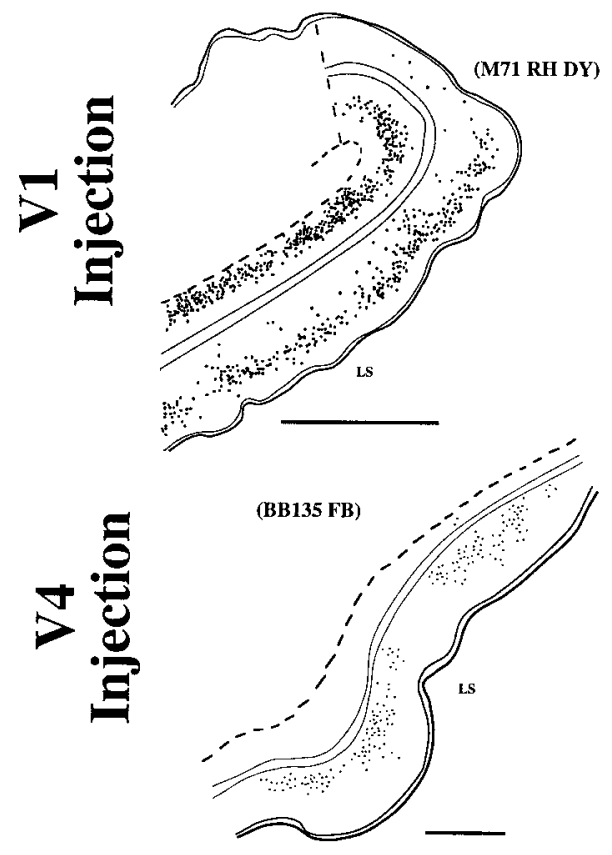

(M71 RH DY)
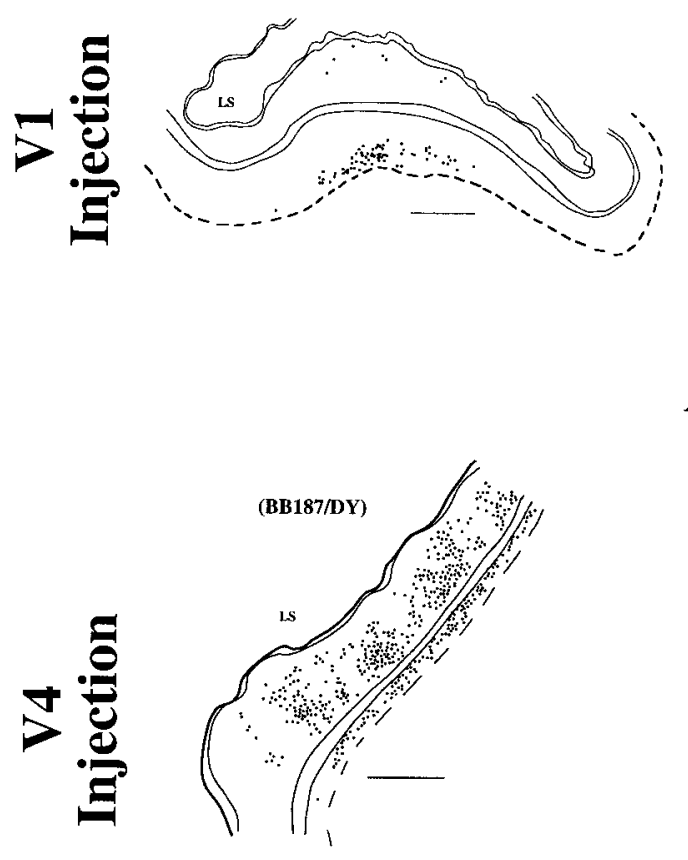

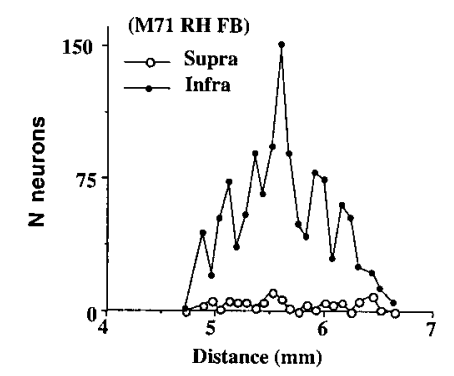

AREA V3A
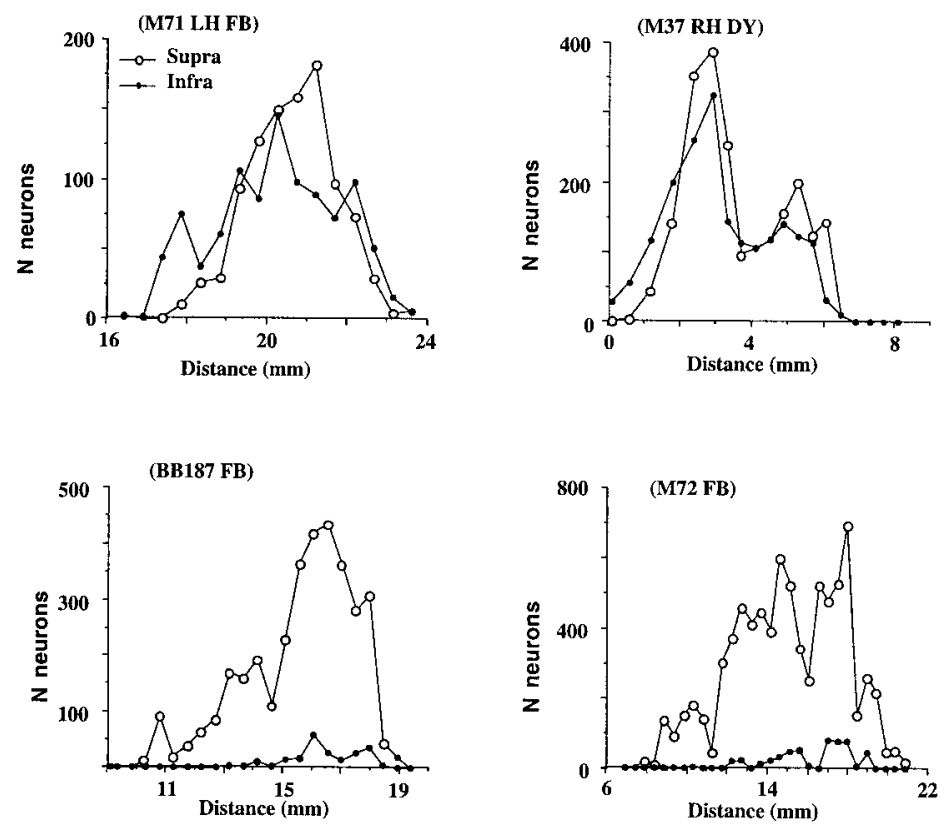

\section{AREA V3}
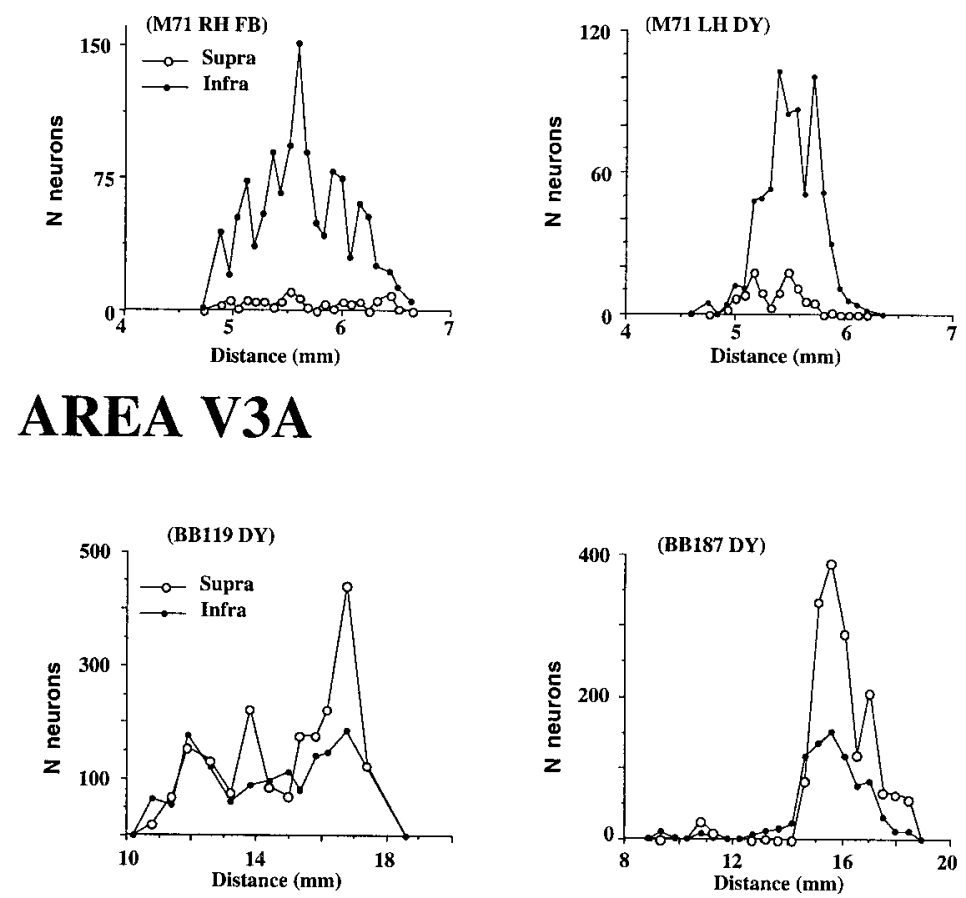

Figure 4. Distribution of retrogradely labeled neurons in extrastriate areas V2, V3, and V3A. Left-hand column, Plots of retrogradely labeled neurons taken from the center of the projection zone as determined from density profiles. Middle and right-hand columns, Neuron density profiles. Plots and neuron density profiles have been chosen from different animals. Scale bars, $1 \mathrm{~mm}$.

areas V1 and V4 were performed in a stereotypical fashion and concerned the representation of the central visual field. This means that one can expect a gap of labeling between adjacent areas when they share a border representing the peripheral visual field. In the present study, injection of area V1 led to weak or no label in area $\mathrm{V} 3 \mathrm{~A}$, and injection of area $\mathrm{V} 4$ gave weak label in area V3, confirming previous findings (Van Essen et al., 1986; Felleman et al., 1997b). This means that injections in area V1 led 

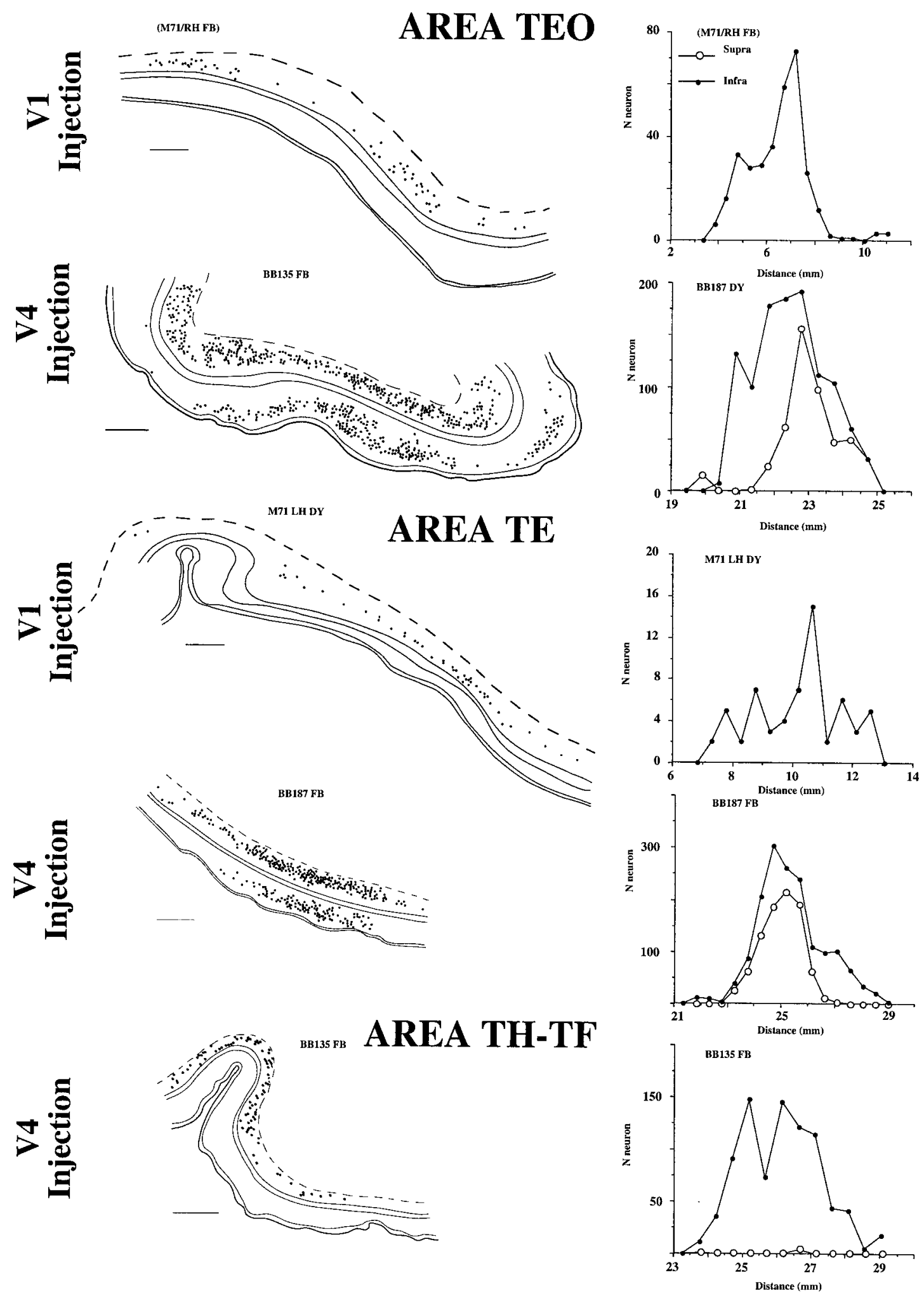

Figure 5. Distribution of retrogradely labeled neurons in ventral stream areas (TEO, TE, and TH-TF). Conventions as in Figure 4.

to extrinsic label in areas V2, V3, V4, MT, FST, LIP, TE, TEO, $\mathrm{TH}-\mathrm{TF}$, and FEF. Injections in area V4 led to labeling in areas V2, V3A, V4t, MT, FST, LIP, TE, TEO, TH-TF, and FEF. Areas that share a border that represents the central visual field and where labeling can be continuous are V4t-V5 and V3A-V4
(Van Essen and Zeki 1978; Gattass et al., 1988; Boussaoud et al., 1991). In the present study, we do not attempt to distinguish label in V4 and V4t. This leaves the possibility of imperfect separation of labeling between V3A-V4 and V4t-MT. This does not influence our main conclusions in the present study for the following 

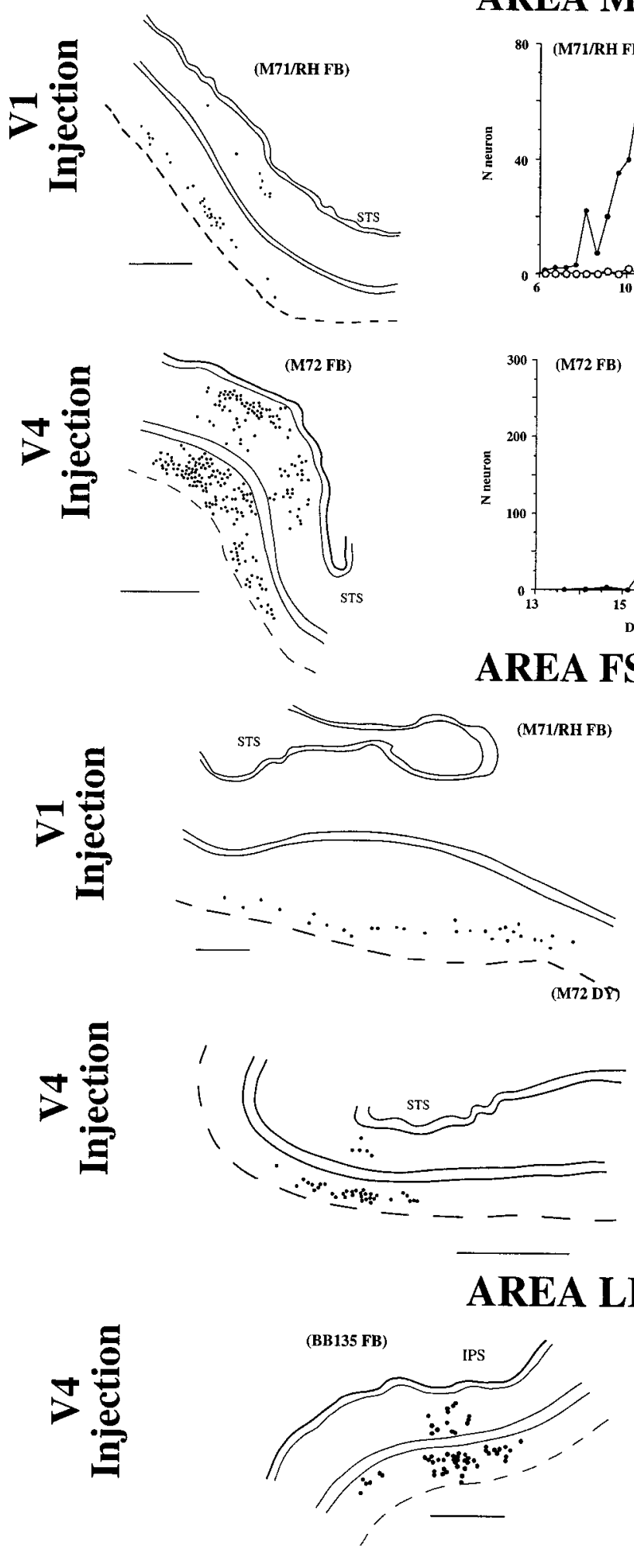

\section{AREA FST}
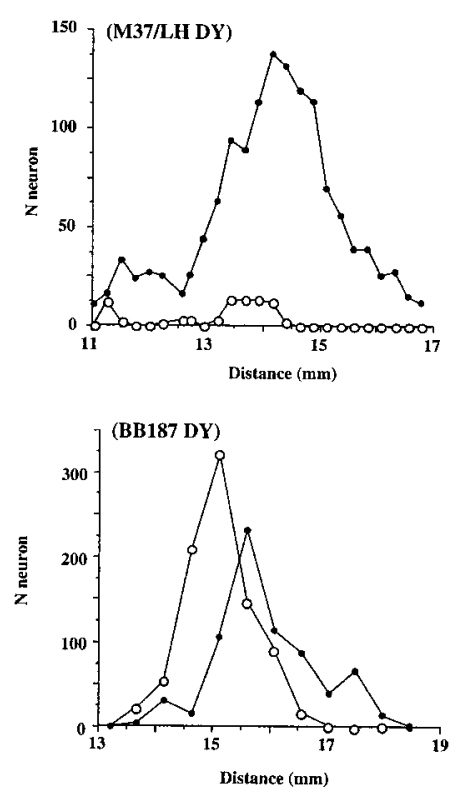
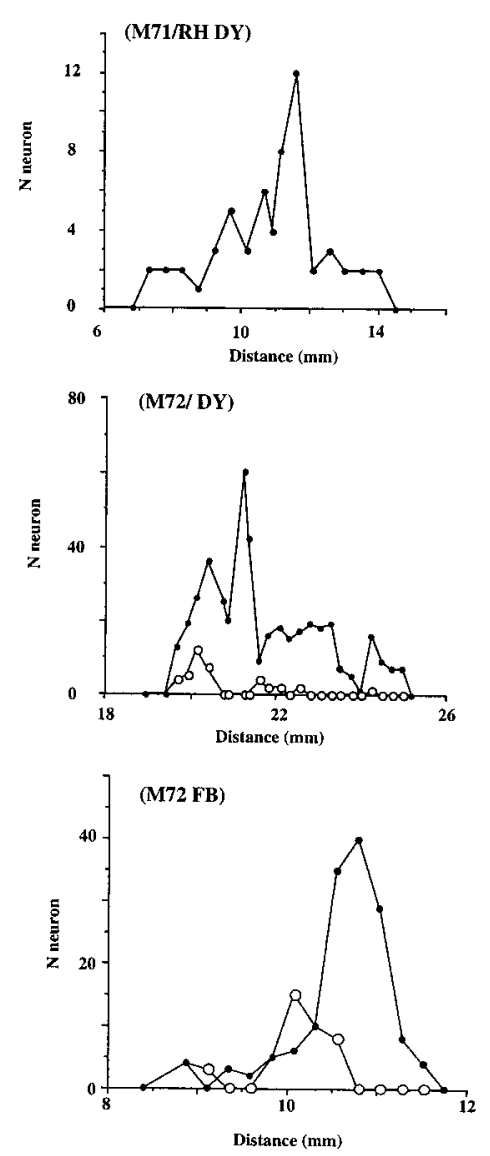

Figure 6. Distribution of retrogradely labeled neurons in dorsal stream areas (MT, FST, and LIP). Conventions as in Figure 4.

reasons. First, because labeling was continuous in V4t-MT after one of seven injections, we can therefore discount an effect of continuous labeling on estimates of SLN\% in area MT. Second, although labeling in V3A-V4 was continuous, this concerned a minority (three of seven) of injections. Quantitative analysis of the V3A projection zones, as illustrated in Figure 1, shows that a $20 \%$ cutoff for this area leads to a $2 \%$ change in SLN\% accompanied by a $1.6 \mathrm{~mm}$ shift of the V3A border. This would put the 


\section{AREA FEF V4 Injection}
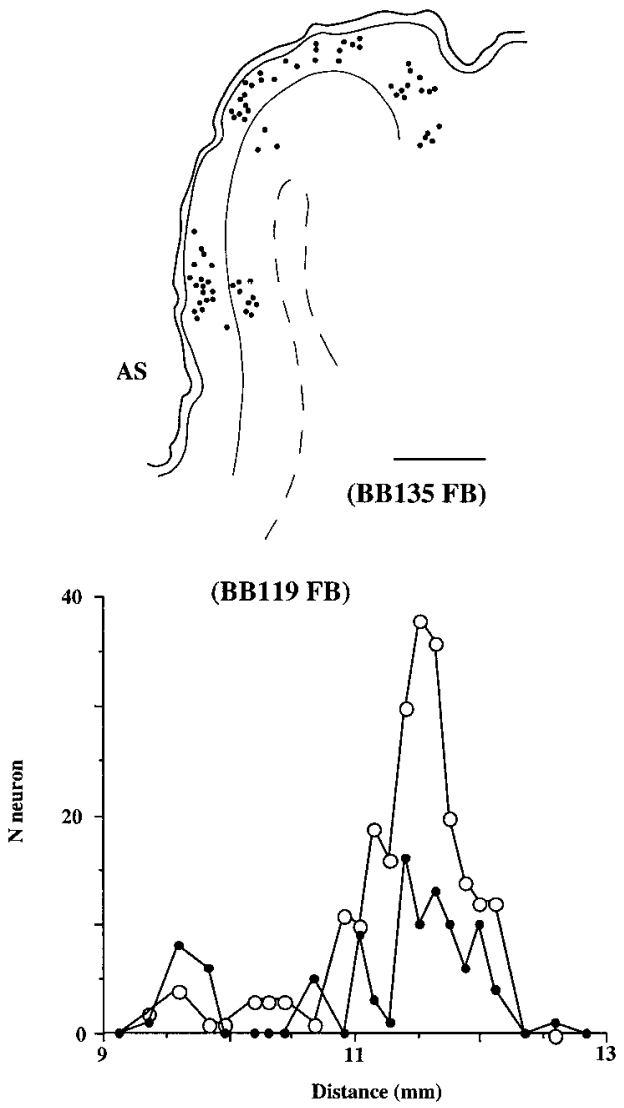

Figure 7. Distribution of retrogradely labeled neurons in FEF. Conventions as in Figure 4.

areal border well outside of the region that is commonly thought to be V4. In other words, if we were to repeat the analysis using a highly conservative location of V3A that would exclude V4t neurons, we would obtain very similar SLN\% values for V3A to those obtained using the full projection zone as in the present study.

\section{Distributions in areas sharing FB and FF projections to both target areas}

After injections in areas V1 and V4 labeled neurons are found in similar densities in supragranular layers of area V2. This contrasts with the densities in infragranular layers, which are relatively high after injections in area V1 and virtually absent after injection in area V4 (Figs. $3 A, 4$ ).

Quantitative results for different injections are reported in Table 1. Altogether labeling was successfully analyzed in area V2 for 11 injections in area V1 and returned a mean value of $48 \%$ SLN (range, 35-55\%). Seven projection zones were analyzed in area $\mathrm{V} 2$ resulting from injection in area V4 and gave a mean SLN value of $93 \%$ (range, $89-99 \%$ ).

In area V3, injections in area V1 led to peak densities in infragranular layers, and four injections gave a mean SLN value of $9 \%$. Injections in V4 led to peak densities in area V3A in supragranular layers (Fig. 4), and the seven injections gave a mean SLN value of $60 \%$ (Table 1).
Figure 4 shows that those cortical areas (i.e., areas V2 and $\mathrm{V} 3 / \mathrm{V} 3 \mathrm{~A}$ ) that have $\mathrm{FB}$ projections to area $\mathrm{V} 1$ and $\mathrm{FF}$ projections to area V4 show complementary patterns of labeled neurons so that FF projections are characterized by high SLN\% and FB by low SLN\%.

\section{Distributions in ventral stream areas}

Areas in the temporal lobe are known to possess FB projections to both areas V1 and V4 (Morel and Bullier 1990; Distler et al., 1993; DeYoe et al., 1994; Felleman et al., 1997a), and the present results show that the density of these projections is considerably higher to area V4 than to area V1 (Fig. 5). Whereas the FB projections to area V1 from both TEO and TE are exclusively from infragranular layers, the FB projections to area V4 show large SLN\% values. In TEO and TE, four projection zones from $\mathrm{V} 1$ injections were analyzed and returned a mean SLN\% inferior to $0.5 \%$, whereas the seven projection zones after V4 injections returned a mean SLN\% of $40 \%$ in TEO and $26 \%$ in TE (Table 1).

Labeled neurons are present in the parahippocampal areas after injections in areas V1, confirming results of others (Rockland and Van Hoesen, 1994). However, these neurons were extremely sparse and exclusively located in infragranular layers (Table 1). Labeling in TH-TF was reasonably strong after injection in area V4, and labeled neurons were almost exclusively located in the infragranular layers (Fig. 5, bottom).

\section{Distributions in FB and lateral projections from dorsal stream areas}

Areas MT and FST both belong to the dorsal stream and are known to project to areas V1 and V4 (Maunsell and Van Essen, 1983; Kennedy and Bullier, 1985; Perkel et al., 1986; Ungerleider and Desimone, 1986; Tanaka et al., 1990; DeYoe et al., 1994; Rockland and Van Hoesen, 1994; Hof et al., 1996). MT is thought to have a FB projection to area V1 and a lateral projection (i.e., connecting areas on equivalent hierarchical levels) to area V4 (Maunsell and Van Essen 1983; Ungerleider and Desimone, 1986). The density and laminar distribution of the labeled neurons in MT are seen to differ to a large extent according to their target (Fig. 6, top). The FB projection from MT to area V1 showed low densities with the majority of labeled neurons principally in the infragranular layers, whereas the densities of labeled neurons projecting to area V4 were considerably higher and equally distributed in supragranular and infragranular layers. In MT, nine projection zones from V1 injections were analyzed and returned a mean SLN\% value of 5\%, whereas the seven projection zones after V4 injections returned a mean SLN\% value of $47 \%$ (Table 1).

Area FST possesses FB projections to both areas V1 and V4 (Boussaoud et al., 1990; Tanaka et al., 1990; Felleman et al., 1997a). The density of the FB projection to area V4 was higher than that for the projection to $\mathrm{V} 1$, and whereas all the neurons projecting to area V1 were located in infragranular layers, some labeled neurons were located in supragranular layers after injection in area V4 (Fig. 6, middle). In FST, the seven projection zones after V4 injections returned a mean SLN of 14\% (Table 1).

LIP possesses FB projections to V4 (Cavada and GoldmanRakic, 1989; Andersen et al., 1990; Blatt et al., 1990; Tanaka et al., 1990; Shipp and Zeki, 1995). The present results show that there is a hitherto undescribed projection to area V1 that is however extremely sparse and originated almost exclusively from the infragranular layers (Table 1). The projection from LIP to area V4 was considerably stronger than the V1 projection, and a non- 

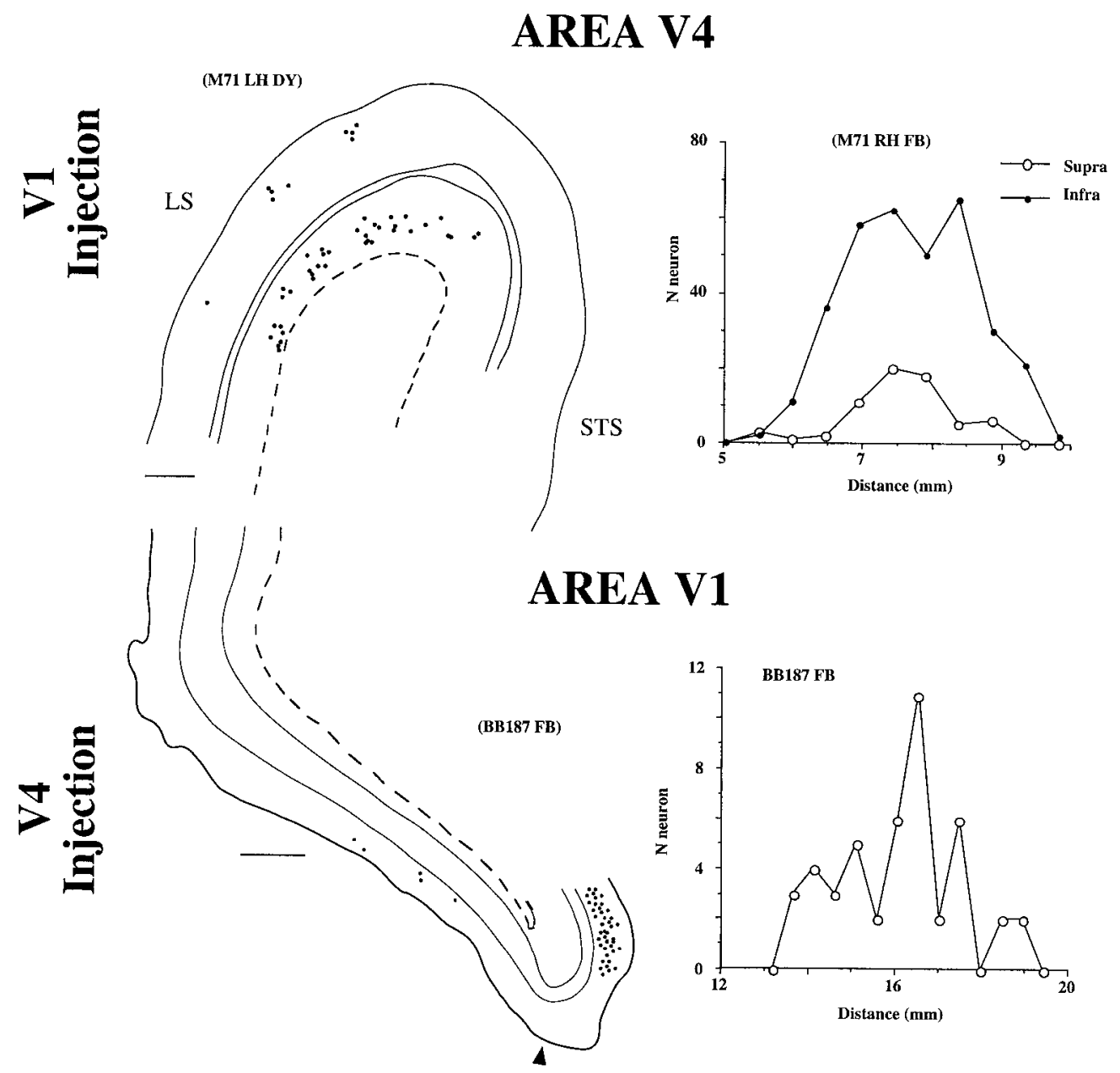

Figure 8. Distribution of retrogradely labeled neurons in areas V4 and V1. The V1-V2 border is indicated by an arrowhead. Conventions as in Figure 4.

negligible proportion of neurons was found in the supragranular layers (Fig. 6, bottom). In LIP the seven projection zones after V4 injections returned a mean SLN\% value of $27 \%$ (Table 1).

\section{Distributions in the FEF}

Several authors have described projections from the FEF to area V4 (Huerta et al., 1987; Schall et al., 1995; Shipp and Zeki, 1995; Stanton et al., 1995; Bullier et al., 1996). In the present study, one of the three cases in which multiple injections were made in area V1 was examined for labeled neurons in FEF and showed a very sparse projection (six labeled neurons) entirely originating from the infragranular layers (Table 1). This result, along with the finding in LIP (see above), confirms that anterior cortical areas that project to area V4 also project to area V1. For the projection of FEF to area V4, the present results show that although it is a weak projection, it is at least as strong as the projection from FST to V4. Surprisingly, after all seven injections in area V4, the projection to area V4 from FEF largely arises from the supragranular layers (mean SLN\% value, 73\%; Fig. 7).

\section{Reciprocal projections between areas V1 and V4}

It has been suggested that reciprocity is a universal feature of corticocortical pathways (Rockland and Pandya, 1979), but in the visual system $\sim 20 \%$ of the connections are unidirectional (Felleman and Van Essen, 1991; Salin and Bullier, 1995). We have been able to examine this issue directly for connections linking areas V1 and V4. The top part of Figure 8 shows typical labeling in area V4 after injection in area V1. This gives a range of numbers of neurons per section in the order of 10-60 (Table 1). This contrasts with the results in area V1 after injection in area V4. Of the seven projection zones analyzed in area V1, that illustrated by the density profile in Figure 8 has the highest number of neurons, the average being less than nine neurons per projection zone, which is $<0.1 \%$ of the intensity of the V4 to V1 projection (Table 1).

\section{Distribution of intrinsic labeled neurons}

Labeled neurons within the area injected showed very high densities and typically extended further in area V4 than in area V1 (Fig. 9), confirming the results of others (Yoshioka et al., 1992). The four projection zones analyzed returned a mean SLN of $61 \%$ in area V1 and in $64 \%$ in area V4 (Table 1). It could be that part of the labeled neurons located close to the injection sites are interneurons. Because extrinsic connections are uniquely from pyramidal neurons, we wanted to restrict our measurement to the pyramidal population of intrinsic neurons. By deleting from the counts the labeled cells at a distance of $<250 \mu \mathrm{m}$ from the pick-up zone, we excluded a large proportion of the inhibitory intrinsic neurons (Tanigawa et al., 1998). Counts of the total population of labeled cells were reduced by $6 \%$ (in area V1) and $12 \%$ (in area V4), but the laminar distribution remained stable (paired $t$ test; $p>0.05$ ) in both areas (V1, SLN\%: 63 vs 61\%; V4, SLN\%: 65 vs 64\%). 

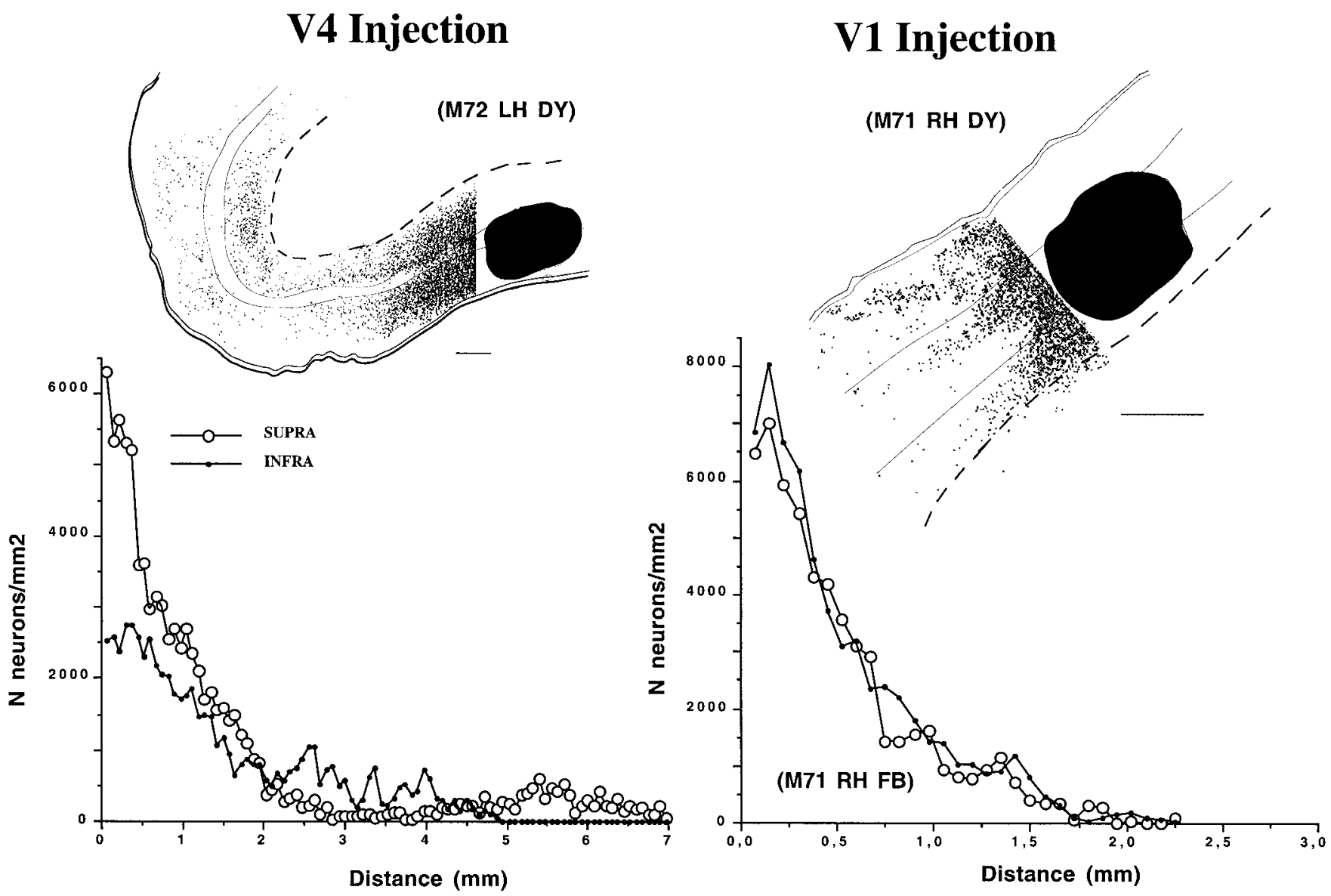

Figure 9. Distribution of retrogradely labeled intrinsic neurons. Scale bar, $0.5 \mathrm{~mm}$. Conventions as in Figure 4.

\section{SLN\% characterizes individual projections}

The SLN\% values in the projections to areas V1 and V4 for individual injections are shown in Table 1, and a summary of the means are provided in Figure 10. Statistical analysis (Table 2) reveals that SLN\% values vary across areas for V1 (multinomial ANOVA, $p<0.001)$ and V4 afferents $(p<0.001)$. In all animals in which a double injection was performed, the analysis did not reveal statistical variability because of the type of dye used (FB vs DY; all cases $p>0.05$ ). Furthermore, in cases of V4 injections in which complete data from all the projecting areas were obtained, the multinomial ANOVA did not show statistical variations across subjects $\left(\chi^{2}=4.75 ; p=0.09\right)$. Comparisons of the SLN\% values for adjacent hierarchical levels (as determined by the scheme of Felleman and Van Essen, 1991) showed that of the total 46 comparisons, 41 were statistically significant (Table 2). This analysis shows that each projection is characterized by a specific SLN\% value.

Hence, injections in area V1 showed a significant stepwise decrease in SLN\% in the sequence V2-V3. Beyond V4 there was a significant stepwise decrease in percentages in the dorsal stream going from MT to FST and in the ventral stream in the sequence V4-TEO-TE-TH-TF. However, our results did not show a significant decrease in SLN\% going from V3 to V4 despite the fact that it has been reported that V3 has a FF type projection to area V4 (Felleman et al., 1997a).

Injection in area V4 showed a significant stepwise decrease in SLN\% values in the ascending pathway in the sequence V1-V2$\mathrm{V} 3 \mathrm{~A}$. In the feedback pathways, there was a significant stepwise decrease in the percentages in the dorsal pathways in the sequence MT-LIP-FST and in the ventral pathway in the sequence TEO-TE-TH-TF.

These results suggest that in the case of FB connections the greater the projection distance, the more it involves cells located in the infragranular layers. For FF projections the converse is true so that there is a proportional increase in SLN\% with increasing distance.

\section{SLN\% and hierarchical organization of the visual system}

We have used the Felleman and Van Essen (1991) hierarchical model of the visual system shown in Figure $11 A$ and related it to the SLN\% of V1 and V4 afferents. For each connection we have calculated the number of hierarchical steps separating the interconnected areas (Fig. 11B). For example, areas V1, V2, and V4 are on hierarchical levels 1,2 , and 5 , respectively. In the case of the FB projection from $\mathrm{V} 2$ to $\mathrm{V} 1$, the projection crosses one level in a positive direction (difference of levels: $2-1=+1$ ). The FF projection from V2 to V4 crosses three levels, but the difference is negative (difference level: $2-5=-3$ ). In this way numbers of hierarchical steps ranges from -4 (FF pathway going from V1 to $\mathrm{V} 4)$ to +9 (FB pathway going from $\mathrm{TH}-\mathrm{TF}$ to $\mathrm{V} 1$ ).

The relationship between the SLN\% values and number of hierarchical steps is highly consistent across the 20 corticocortical pathways projecting to areas V1 and V4 (Fig. 11C). The correlation factor for the pooled SLN\% values is high $\left(r^{2}=0.77\right)$ and statistically significant (Spearman; Rho $=-0.89 ; p=0.0001$ ). 

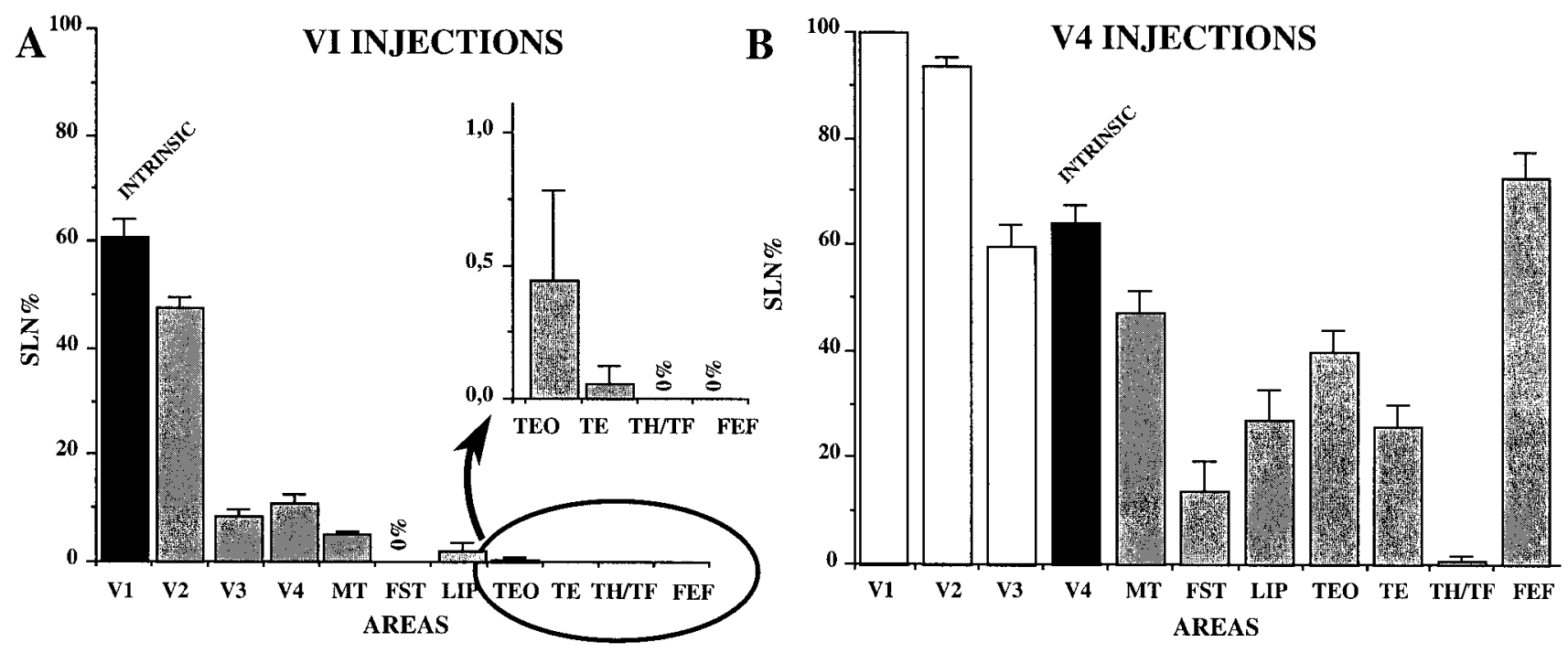

Figure 10. Histograms of the mean SLN\% values in individual cortical areas that project to areas V1 $(A)$ and V4 (B). In each case, FB ( gray bars), FF (white bars), and intrinsic projections (black bars) are distinguished.

\begin{tabular}{|c|c|c|c|c|c|c|c|c|c|c|}
\hline & & & & $\mathrm{V}^{3}$ & & V4 & & MT & & FST \\
\hline \multicolumn{11}{|c|}{ V1 injections } \\
\hline $\mathrm{V} 2$ & & & & \multicolumn{2}{|c|}{$<$} & \multicolumn{2}{|l|}{$<$} & \multicolumn{2}{|l|}{$<$} & $<$ \\
\hline V3 & \multicolumn{3}{|c|}{$* *$} & & \multicolumn{2}{|l|}{$=$} & \multicolumn{2}{|l|}{$<$} & $<$ \\
\hline V4 & \multicolumn{3}{|c|}{$* *$} & \multicolumn{2}{|c|}{ NS } & & & \multicolumn{2}{|l|}{$<$} & $<$ \\
\hline MT & \multicolumn{3}{|c|}{$* *$} & Ns & & $* *$ & & \multirow{2}{*}{\multicolumn{2}{|c|}{$* *$}} & $<$ \\
\hline \multirow[t]{2}{*}{ FST } & & \multicolumn{2}{|c|}{$* *$} & \multicolumn{2}{|c|}{$* *$} & $* *$ & & & & \\
\hline & $\mathrm{V} 1$ & $\mathrm{~V} 2$ & V3A & MT & FST & LIP & TEO & $\mathrm{TE}$ & $\mathrm{TH} / \mathrm{TF}$ & FEF \\
\hline \multicolumn{11}{|c|}{ V4 injections } \\
\hline $\mathrm{V} 1$ & & $<$ & $<$ & $<$ & $<$ & $<$ & $<$ & $<$ & $<$ & $<$ \\
\hline $\mathrm{V} 2$ & NA & & $<$ & $<$ & $<$ & $<$ & $<$ & $<$ & $<$ & $<$ \\
\hline V3A & NA & $* *$ & & $<$ & $<$ & $<$ & $<$ & $<$ & $<$ & $\geq$ \\
\hline MT & NA & $* *$ & $* *$ & & $<$ & $<$ & $\leq$ & $<$ & $<$ & $>$ \\
\hline FST & NA & $* *$ & $* *$ & $* *$ & & $>$ & $>$ & $>$ & $<$ & $>$ \\
\hline LIP & NA & $* *$ & $* *$ & $* *$ & $* * *$ & & $>$ & $\leq$ & $<$ & $>$ \\
\hline TEO & NA & $* *$ & $* *$ & $* / \mathrm{NS}$ & $* *$ & $* *$ & & $<$ & $<$ & $>$ \\
\hline TE & NA & $* *$ & $* *$ & $*$ & $* *$ & $* / \mathrm{NS}$ & $* *$ & & $<$ & $>$ \\
\hline $\mathrm{TH} / \mathrm{TF}$ & NA & $* *$ & $* *$ & $* *$ & $* *$ & $* *$ & $* *$ & $* *$ & & $>$ \\
\hline FEF & NA & $* *$ & */NS & $* *$ & $* *$ & $* *$ & $* *$ & $* *$ & $* *$ & \\
\hline
\end{tabular}

V1 injections, $\chi^{2}=1988 ; p<0.001 ;$ V4 injections, DY, $\chi^{2}=14,073 ; p<0.001 ; \mathrm{FB}, \chi^{2}=14073 ; p<0.001$.

Multinomial ANOVA was used to test differences in SLN\% across visual areas. $\chi^{2}$ and $p$ values are provided. Analysis of labeling resulting from V1 injection was performed using values obtained in case M71 (both hemispheres) in which SLN\% values were obtained in all the projecting areas (Table 1). Dyes, sides, and areas were treated as between-group factors. After V4 injections, the analyses were performed on values obtained from each dye separately, and subjects and areas were treated as between-group factors. Statistical levels of significance are indicated for the planned comparisons of SLN $\%$ between pairs of area (NS, Not significant; ${ }^{*} p<0.01 ; * * p<0.001$ ). These comparisons are used to rank pairs of areas (higher, >; lower, <; same level, =. Ex: Area V2 is lower than area V3.). Because of a small number of labeled cells in V1 after V4 injections (range, $0-46$ cells per animal; Table 1) the power of the statistical test is greatly reduced, and when planned comparisons did not reach the significance level (as for example V1 vs V3; i.e., 100 vs 60 SLN\%), we cannot affirm if it is real or attributable to the small sample size. Paired comparisons with V1 have been omitted in this table (NA).

The correlation is not generated by one of the two sets of afferents because the same analysis for V1 and V4 independently generates only a slightly lower correlation factor $\left(\mathrm{V} 1, r^{2}=0.69\right.$; $\mathrm{V} 4, r^{2}=0.70$ ), which remains highly significant (Spearman; V1: Rho $=-0.87 ; p=0.004 ; \mathrm{V} 4$, Rho $=-0.73 ; p=0.02)$.

Figure $11 C$ shows that the pooled values of SLN\% for individ- ual projections correlate remarkably well with numbers of hierarchical steps. Figure $12 A$ shows the correlation of SLN\% values with hierarchy for individual V4 injections. For individual cases, variations are small both for the slopes (Fig. 12B; mean, $-9.41 \pm$ 0.36 ) and the correlation factors (Fig. $12 C$; mean, $0.66 \pm 0.03$ ), and are statistically significant in all cases (Spearman; all cases 


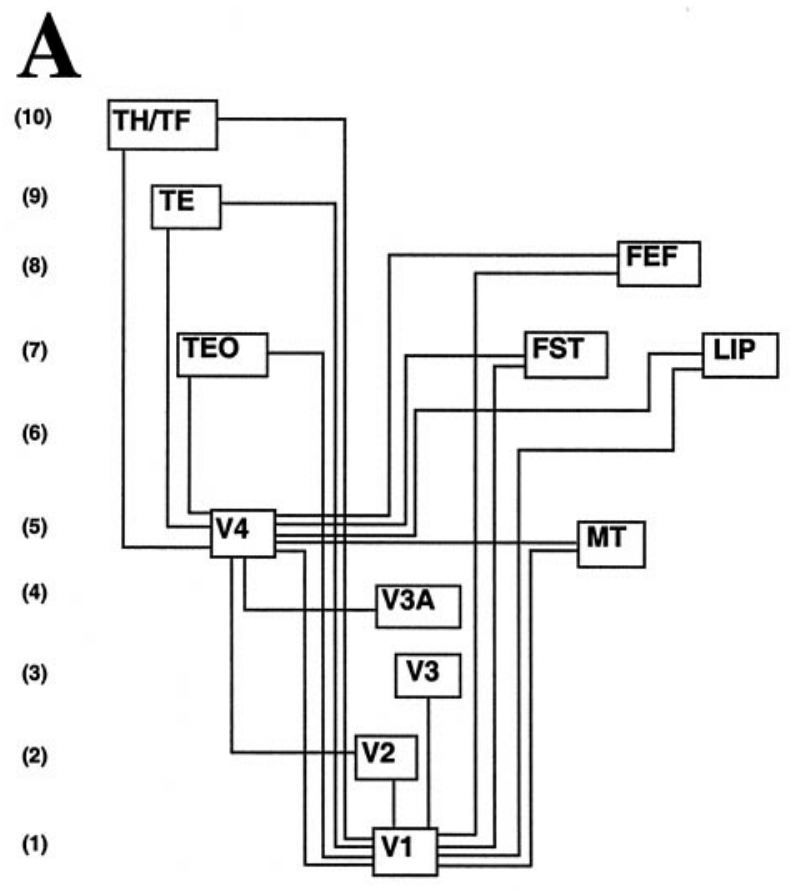

LEVEL (from Felleman and Van Essen 1991)
C

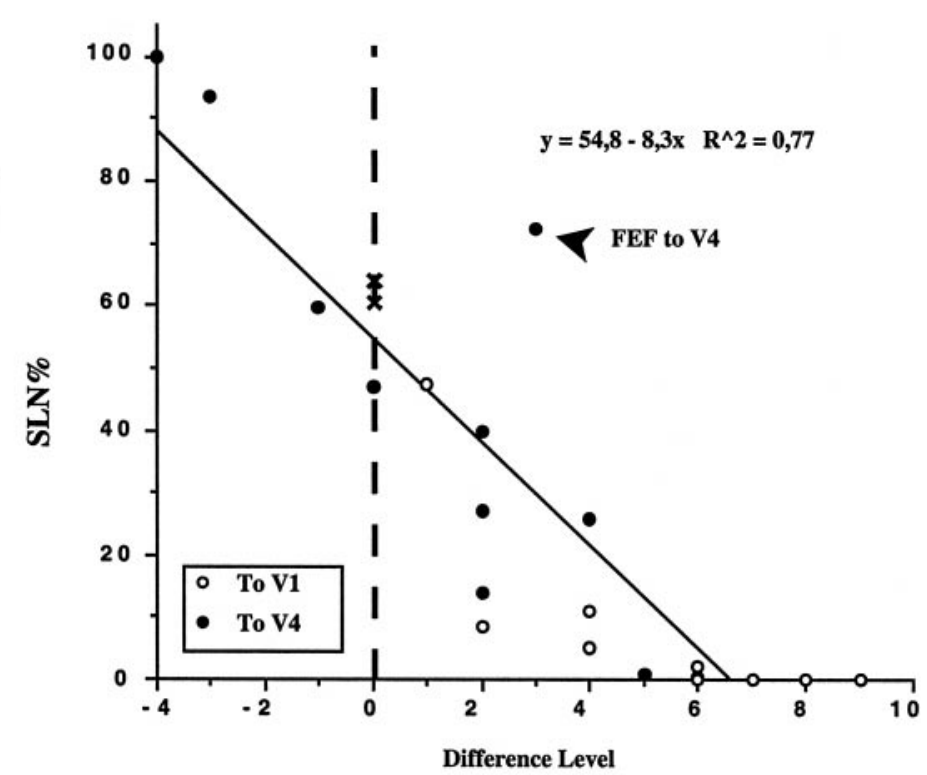

\begin{tabular}{|c|c|c|c|c|c|c|c|c|c|c|c|c|}
\hline AREA & V1 & V2 & V3 & V3A & V4 & TEO & TE & TH-TF & MT & FST & LIP & FEF \\
\hline LEVEL & 1 & 2 & 3 & 4 & 5 & 7 & 9 & 10 & 5 & 7 & 7 & 8 \\
\hline DISTANCE FROM V1 & 0 & 1 & 2 & & 4 & 6 & 8 & 9 & 4 & 6 & 6 & 7 \\
\hline DISTANCE FROM V4 & -4 & -3 & & -1 & 0 & 2 & 4 & 5 & 0 & 2 & 2 & 3 \\
\hline
\end{tabular}

Figure 11. A, Felleman and Van Essen (1991) hierarchical model of the visual system. B, Table indicating the number of levels separating individual areas from areas V1 and V4. C, Correlation of SLN\% with the numbers of hierarchical levels calculated from the model of Felleman and Van Essen (1991). Crosses correspond to intrinsic values. Arrowhead points toward the SLN\% value observed for the FEF to V4 projection.

$p<0.05)$. For individual injections in both areas V1 and V4 we found that pairwise comparison of hierarchical relationship shows a $77 \%$ (range, 71-90\%) fit with the Felleman and Van Essen (1991) model. This fit increases to 82\% (range, 78-90\%) if FEF is not included. These results are highly significant because they show that hierarchical relations can be inferred from the results of a single injection, provided the SLN\% values are accurately determined for all areas projecting to the target area.

Malcolm Young's group has claimed that the precise ordering of the monkey visual areas cannot be specified exactly, mostly because of incertitude about the hierarchical levels of areas located at higher stages (Hilgetag et al., 1996a). However they have proposed an optimal peak hierarchy (Hilgetag et al., 1996b) that overlaps with a large number of solutions. Using this model we found that the laminar pattern of projections to V1 and V4 is highly correlated to the hierarchical organization of the visual system $\left(r^{2}=0.61\right.$; Spearman, Rho $\left.=-0.83 ; p=0.0001\right)$.

\section{Hierarchy suggested by areal differences of SLN\%}

We have used the SLN\% values to modify the Felleman and Van Essen (1991) model. Statistical tests (see Materials and Methods; Table 2) differentiated areas according to their SLN\% after V1 or V4 injections and consequently placed them on distinct hierarchical levels (Fig. 13). Injections in area V4 values place areas V1 and V2 on successive levels. Area V3A (60\%) is on a level immediately below area V4. Injections in V1 place V1, V2, and $\mathrm{V} 3$ on successive levels but fail to separate areas V3 and V4. This would suggest that the hierarchical distance separating area V3 and V4 is small, and we therefore placed V3 on a level just below V4. Injections in V1 show that the SLN\% in MT is lower than in V4, suggesting that MT is on a higher level than V4. V4 injections suggest that MT and TEO are on the same level. V4 injections place LIP below FST on the same level as TE. TH-TF have minimum SLN\% values and are placed at the highest level. We left one empty level below areas TH-TF to eventually accommodate areas (such as area $7 \mathrm{a}$ and the polysensory areas of the superior temporal sulcus) that are not interconnected with areas V1 and V4 but project to the parahippocampal cortex and are thought to occupy a higher rank than FST (Felleman and Van Essen, 1991).

The model that we have derived from the SLN\% does not make pairwise comparisons of connections between areas, which is the basis of the Felleman and Van Essen (1991) model. Instead rank is directly derived from SLN\%, so that the injections in V1 show that MT is further than V3, which is further than V2. In one sense our handmade approach is a hybrid of the Felleman and Van Essen (1991) model because we have retained discrete levels. It is expected that a mathematical approach will generate a graded distance values between areas and consequently provide a 

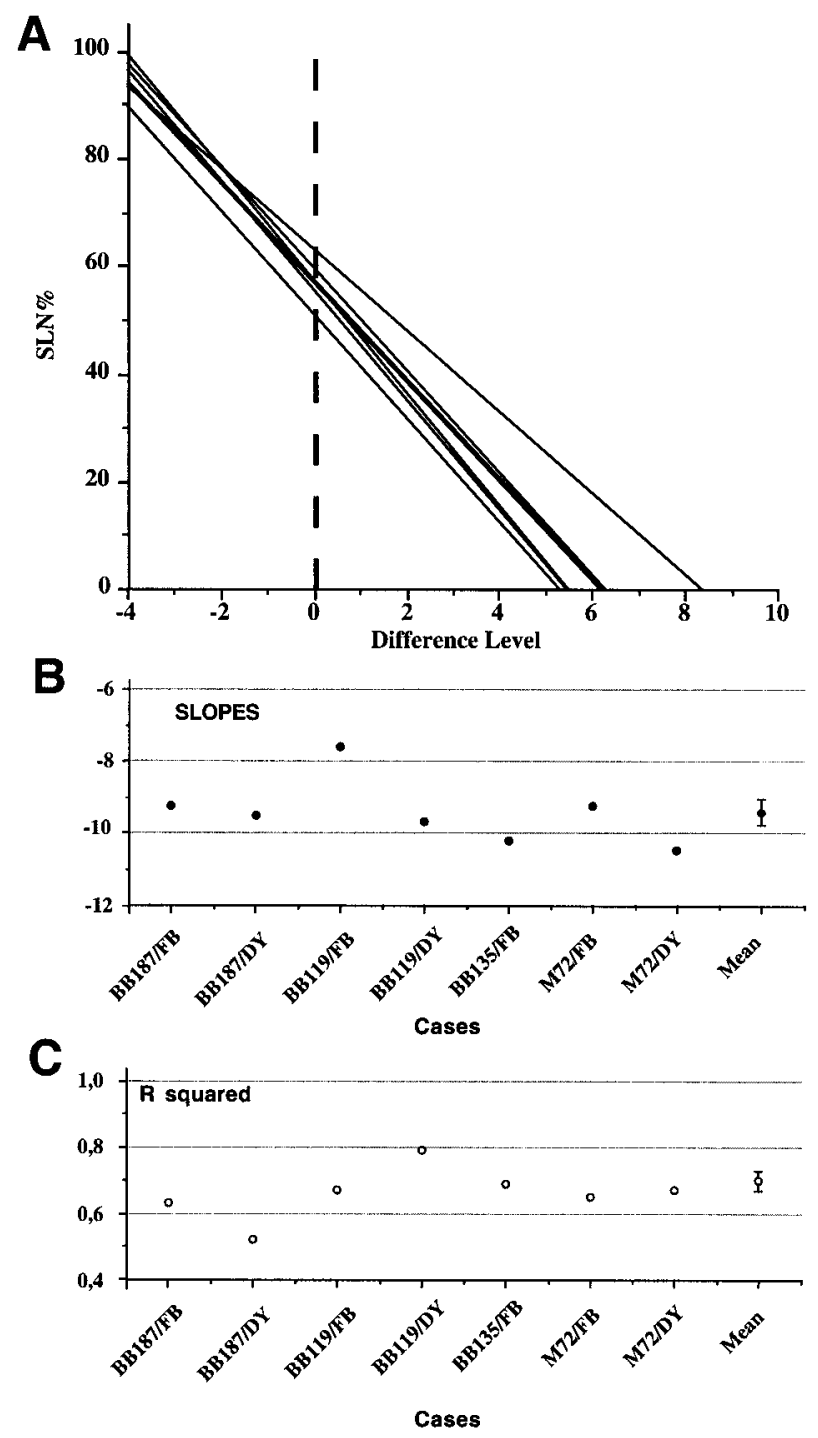

Figure 12. A, Correlation for single injections in area V4 of SLN\% with the number of hierarchical levels that separate individual afferent areas. Slopes $(B)$ and $r^{2}(C)$ calculated from the individual correlograms shown in $A$.

better determinacy of the hierarchical status of the visual areas. The correlation for the Felleman and Van Essen model (1991) $\left(r^{2}\right.$ $=0.77)$ is lower than that proposed above $\left(r^{2}=0.87\right.$; Spearman, Rho $=-0.91 ; p=0.0001)$, indicating that we have successfully optimized hierarchical levels with SLN\% values.

\section{DISCUSSION}

We shall first review in detail how areal relationships suggested by SLN\% values compare to the hierarchical relationships reported in the literature. We shall briefly discuss the relevance of hierarchical schemes for understanding visual processing before concluding on the potential of SLN\% to constrain models of visual cortex.

\section{Ascending pathways}

The projections from areas V1, V2, and V3A to area V4 have been shown to confirm to a FF sequence (DeYoe and Van Essen, 1985; Livingstone and Hubel, 1987; Tanaka et al., 1990; Nakamura et al., 1993; DeYoe et al., 1994; Barone et al., 1995; Felle- man et al., 1997b). After injections in area V4, maximum SLN\% values are located in areas V1 (100\%) and V2 (93\%) and significantly less in area V3A (60\%). Similarly, V2 and V3 send FB projections to area V1, and again the SLN\% in V2 is higher compared to V3 (47 vs 9\%). These results place areas V3 and V3A on a higher level than area V2 in agreement with other reports (Felleman and Van Essen, 1991; Felleman et al., 1997b; Gattass et al., 1997).

Area V3 is reported to have FF projections to area V4 (Felleman et al., 1997b). We find that V1 injections return similar SLN\% values in V3 and V4 and we have shifted area V3 to a level immediately below V4 and on the same level as V3A. Although it has been questioned whether V3 and V3A are distinct areas (Krubitzer and Kaas, 1993), it is claimed, on the basis of qualitative data that V3A and V3 exchange FF and FB projections (Felleman et al., 1997b). Our data suggests only a very small separation of these two areas so we place them on the same level.

\section{Lateral connections}

MT is reported to have a lateral projection to V4 (Maunsell and Van Essen, 1983; Ungerleider and Desimone, 1986). Although after V4 injection, area MT has SLN\% values midway between FF and FB, we have placed this area one level above V4 because (1) V4 and MT have significantly different SLN\% values after injection in V1 and (2) MT SLN\% are significantly different from those of areas V3A and LIP (Table 2), which are reportedly on the hierarchical level below and above MT.

\section{The descending pathways}

The Felleman and Van Essen (1991) model places TH-TF, TE, and TEO on levels 10, 9, and 7. Recent studies support this sequence (Webster et al., 1991; Distler et al., 1993). Our SLN\% values $(1,26$, and $40 \%$ ) suggest that these areas should be on levels 10, 7, and 6 (Fig. 13). These ventral areas send a sparse but consistent FB projection to area V1 (this study; Rockland and Van Hoesen, 1994). Area TEO has significantly higher SLN\% values compared to areas TE and TH-TF, which is compatible with the levels we have allocated to these areas.

Injections of tracers in FST led to labeled cells in LIP in both supragranular and infragranular layers, whereas the terminals are located in all layers (Boussaoud et al., 1990). This has led Felleman and Van Essen (1991) to classify FST and LIP as sharing lateral connections and to place these two areas on the seventh level. FST is reported to exchange FF and FB projections with V4 and MT (Boussaoud et al., 1990). Together these results therefore support the suggestion of Felleman and Van Essen (1991) that areas FST and LIP reside on a level above areas V4 and MT. However, our results return SLN of $27 \%$ for LIP and $14 \%$ for FST, suggesting that these two areas might be on different levels.

To conclude, the Felleman and Van Essen (1991) model contradicts six of the relations suggested by the SLN\%, which are $\mathrm{V} 3=\mathrm{V} 3 \mathrm{~A}$; V4 $<\mathrm{MT}$; MT $=$ TEO; LIP $<$ FST; TEO $<$ FST; $\mathrm{LIP}=\mathrm{TE}(\mathrm{FF}$ is $>, \mathrm{FB}$ is $<$, and lateral is $=)$. Three of the relations suggested by the SLN\% are compatible with the optimal hierarchy proposed by Hilgetag et al. (1996b). There are three categories of disagreements between the two models. First, in the Felleman and Van Essen (1991) model two of these relations were lateral $(\mathrm{MT}=\mathrm{V} 4$ and LIP $=$ FST) (Maunsell and Van Essen, 1983; Ungerleider and Desimone, 1986; Boussaoud et al., 1990). Although we have placed these areas on separate levels based on statistical differences of SLN\%, the distance suggested is small and therefore could be smaller than the nonparametric 

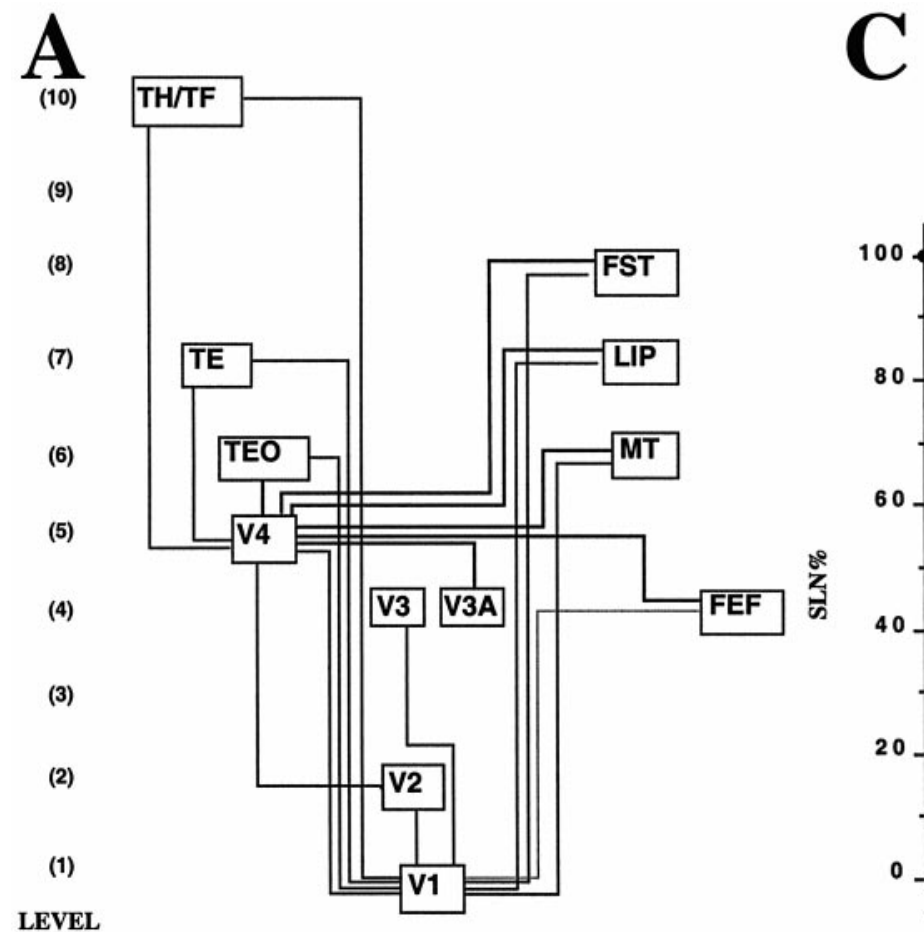

(Modified from Felleman and Van Essen 1991)

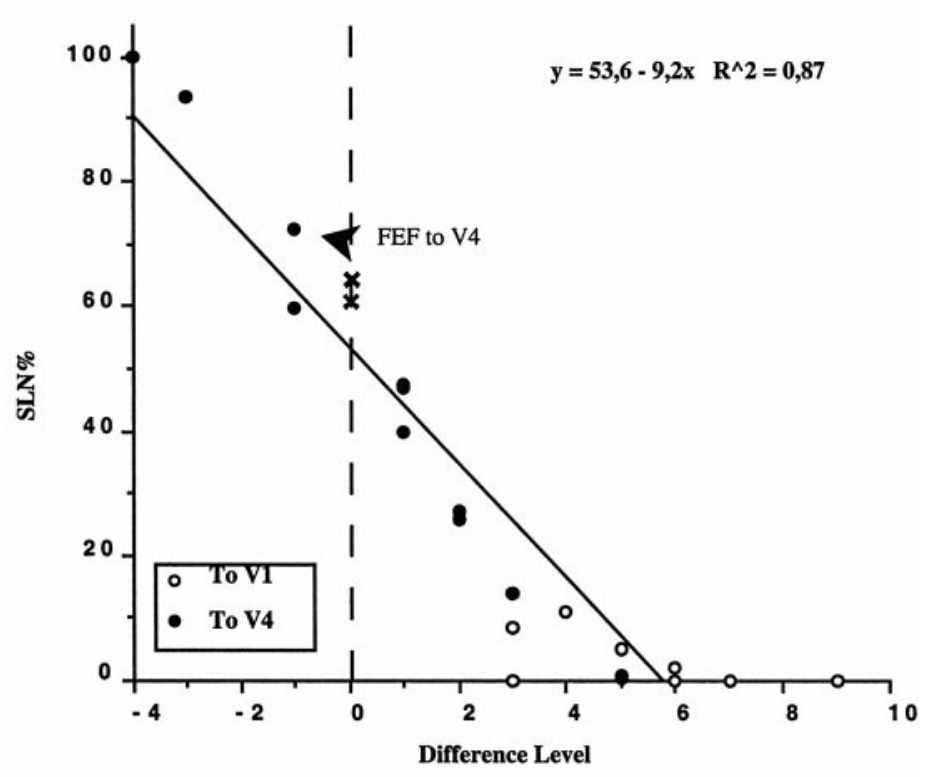

B

\begin{tabular}{|c|c|c|c|c|c|c|c|c|c|c|c|c|}
\hline AREA & V1 & V2 & V3 & V3A & V4 & TEO & TE & TH-TF & MT & FST & LIP & FEF \\
\hline LEVEL & 1 & 2 & 4 & 4 & 5 & 6 & 7 & 10 & 6 & 8 & 7 & 4 \\
\hline DISTANCE FROM V1 & 0 & 1 & 3 & & 4 & 5 & 6 & 9 & 5 & 7 & 6 & 3 \\
\hline DISTANCE FROM V4 & -4 & -3 & & -1 & 0 & 1 & 2 & 5 & 1 & 3 & 2 & -1 \\
\hline
\end{tabular}

Figure 13. Hierarchical model obtained after paired comparison (Table 2) of the proportion of supragranular projecting cells in V1 and V4 afferents. Conventions as in Figure 11.

value of a level in the Felleman and Van Essen (1991) model. Second, some of the differences of the two models concern connections that have been reported as weak and/or inconsistent (MT-TEO; TEO-FST) (Morel and Bullier, 1990; Distler et al., 1993). Third, our suggestion that LIP $=\mathrm{TE}$ is in agreement with Webster et al. (1994). Finally, in our model V3 = V3A, where as in the Felleman and Van Essen (1991) model V3 $<$ V3A. Once again this could be attributable to the SLN\% model detecting small differences that are not easily detected by the laminar analysis used in the Felleman and Van Essen (1991) model, which relies largely on qualitative data.

\section{Relationship of visual areas with FEF}

It is known that area V4 projects to FEF in an FF manner (Barbas and Mesulam, 1981). However, little is known about the reciprocal projection. Despite the absence of any quantitative data, Felleman and Van Essen (1991) have allocated FEF to the eighth level, and accordingly it should possess a strong FB connection to area V4. However, our results do not show projections from FEF to area V4 to be FB projections, because they show a SLN\% of $72 \%$ indicative of FF. Alternatively we cannot exclude the possibility that anatomical characterization of FF and FB connections do not extend to the frontal cortex (Webster et al., 1994).

A number of other anatomical studies question putting FEF at the top of the hierarchical series. In the ventral stream, injections of retrograde and anterograde tracers in TEO revealed lateral connections with FEF (Distler et al., 1993; Webster et al., 1994; Schall et al., 1995). Likewise, injections of anterograde tracers in TE suggested that this structure exhibits $\mathrm{FB}$ projections to FEF, whereas retrograde tracers injected in TE suggest a lateral connectivity with FEF (Webster et al., 1994). Anterograde and retrograde tracer investigations of the relationship of FEF with the dorsal stream failed to give conclusive results with respect to FF and FB classification schemes (Boussaoud et al., 1990; Schall et al., 1995).

There is physiological evidence in favor of FEF not having a purely FB relationship with extrastriate visual areas. Many neurons in FEF respond to visual stimulation with shorter latencies than a large proportion of neurons in more caudal extrastriate visual areas (Bullier and Nowak, 1995; Thompson et al., 1996; Nowak and Bullier, 1997; Schmolesky et al., 1998). One possible cortical route for such early visual responses in FEF is via V1 projections to MT (Maunsell and Van Essen, 1983; Ungerleider and Desimone, 1986).

\section{Physiological significance of hierarchical organizations}

Our results suggest that the relative proportion of supragranular and infragranular layer neurons is a general defining feature, at least in the visual system, of FB and FF pathways. Differences in 
the SLN\% in different pathways could be of functional significance, given the experimental evidence suggesting that pyramidal neurons in upper and lower layers have different physiological properties (Lagae et al., 1989; Douglas and Martin, 1991; Nowak et al., 1995; Raiguel et al., 1995; Ahmed et al., 1998), histochemical features (Hof et al., 1996, 1997), and topographical relationships (Barbas, 1995; Barone et al., 1995). These different properties could contribute to shaping the function of FF in the construction of receptive fields (Zeki 1993; Bullier et al., 1994; Hubel 1995; Vanduffel et al., 1997) and FB pathways in visual imagery (Ishai and Sagi, 1995; Miyashita 1995) and figure ground discriminations (Zipser et al., 1996; Hupé et al., 1998; Lamme et al., 1998).

\section{Hierarchical distance and the organization of visual areas}

The analysis of topology and patterns of laminar connectivity converge to indicate a hierarchical organization of the cortical visual system (Felleman and Van Essen, 1991; Young, 1992). Hierarchy in the Felleman and Van Essen (1991) model is derived from the pairwise analysis of the laminar patters of interareal connectivity in which each connection is defined as an FF, $\mathrm{FB}$, and lateral connection largely on the basis of nonquantitative data. Mathematical modeling of the same database confirms the hierarchical nature of the organization but importantly indicates that there are huge number of possible solutions (Hilgetag et al., 1996a). This indeterminate nature of the proposed organization in part stems from the absence of an indication of the distance separating levels in the hierarchical scheme. The present study shows that the SLN\% for a set of areas leads to an interareal ranking, which largely fits with the Felleman and Van Essen (1991) model. This suggests that SLN\% reflects an underlying functional principle and further provides an indication of the relative hierarchical distance separating areas. A distance rule of hierarchical relationships derived from SLN\% values might be a universal feature of the organization of the cortex, as revealed by the laminar organization of afferents to the frontal lobe (Barbas, 1986) and to the somatosensory system in the monkey (Batardière et al., 1998b). Future modeling of an extended quantitative database of this type holds the promise of providing a determinate model of the organization of visual cortex. The present database based on laminar location of parent cell bodies does not exclude the possibility that quantitative analysis of the laminar location of axon terminals (Barbas and Rempel-Clower, 1997) might be equally important and possibly complementary.

Our analysis of the hierarchical relationships of the visual areas is based on the nomenclature provided in the review paper of Felleman and Van Essen (1991). However, the definition and the integrity of some of these visual areas is still under debate (Kaas, 1996) and will have to be taken into account in future models of the visual cortex. Furthermore, heterogeneity of individual areas, such as a differential representation of the central and peripheral fields, might be accompanied by changes in connectivity with eccentricity (Perkel et al., 1986; Baizer et al., 1991; Stepniewska and Kaas, 1996; Gattass et al., 1997), which in turn could lead to differences in the hierarchical relationships of cortex subserving the central and peripheral visual fields (Falchier et al., 2000).

\section{REFERENCES}

Ahmed B, Anderson JC, Douglas RJ, Martin KA, Whitteridge D (1998) Estimates of the net excitatory currents evoked by visual stimulation of identified neurons in cat visual cortex. Cereb Cortex 8:462-476.
Amaral DG, Insausti R, Cowan WM (1987) The entorhinal cortex of the monkey: I. Cytoarchitectonic organization. J Comp Neurol 264:326-355.

Andersen RA, Asanuma C, Essick G, Siegel RM (1990) Corticocortical connections of anatomically and physiologically defined subdivisions within the inferior parietal lobule. J Comp Neurol 296:65-113.

Baizer JS, Ungerleider LG, Desimone R (1991) Organization of visual inputs to the inferior temporal and posterior parietal cortex in macaques. J Neurosci 11:168-190.

Baleydier C, Morel A (1992) Segregated thalamocortical pathways to inferior parietal and inferotemporal cortex in macaque monkey. Vis Neurosci 8:391-405.

Barbas H (1986) Pattern in the laminar origin of corticocortical connections. J Comp Neurol 252:415-422.

Barbas H (1995) Pattern in the cortical distribution of prefrontally directed neurons with divergent axons in the rhesus monkey. Cereb Cortex 5:158-165.

Barbas H, Mesulam MM (1981) Organization of afferent input to subdivisions of area 8 in the rhesus monkey. J Comp Neurol 200:407-431.

Barbas H, Rempel-Clower N (1997) Cortical structure predicts the pattern of corticocortical connections. Cereb Cortex 7:635-646.

Barone P, Dehay C, Berland M, Kennedy H (1994) Developmental changes in the distribution of acetylcholinesterase in the extrastriate visual cortex of the monkey. Dev Brain Res 77:290-294.

Barone P, Dehay C, Berland M, Bullier J, Kennedy H (1995) Developmental remodeling of primate visual cortical pathways. Cereb Cortex $5: 22-38$.

Batardière A, Barone P, Berland M, Kennedy H (1998b) Laminar reorganization of feedback projections in the primate somatosensory cortex during development. Eur J Neurosci [Suppl] 10:136.

Batardière A, Barone P, Dehay C, Kennedy H (1998a) Area-specific laminar distribution of cortical feedback neurons projecting to cat area 17: quantitative analysis in the adult and during ontogeny. J Comp Neurol 396:493-510.

Beck PD, Kaas JH (1999) Cortical connections of the dorsomedial visual areas in old world macaque monkeys. J Comp Neurol 406:487-502.

Blatt GJ, Andersen RA, Stoner GR (1990) Visual receptive field organization and cortico-cortical connections of the lateral intraparietal area (area LIP) in the macaque. J Comp Neurol 299:421-445.

Boussaoud D, Ungerleider LG, Desimone R (1990) Pathways for motion analysis: cortical connections of the medial superior temporal and fundus of the superior temporal visual areas in the macaque. J Comp Neurol 296:462-495.

Boussaoud D, Desimone R, Ungerleider LG (1991) Visual topography of area TEO in the macaque. J Comp Neurol 306:554-575.

Bruce CJ, Goldberg ME (1985) Primate frontal eye fields. I. Single neurons discharging before saccades. J Neurophysiol 53:603-635.

Bullier J, Nowak LG (1995) Parallel versus serial processing: new vistas on the distributed organization of the visual system. Curr Opin Neurobiol 5:497-503.

Bullier J, Kennedy H, Salinger W (1984) Branching and laminar origin of projections between visual cortical areas. J Comp Neurol 228:328-341.

Bullier J, Girard P, Salin PA (1994) The role of area-17 in the transfer of information to extrastriate visual cortex. In: Cerebral cortex, Vol 10 (Peters A, Rockland KS, eds), pp 301-330. New York: Plenum.

Bullier J, Schall JD, Morel A (1996) Functional streams in occipitofrontal connections in the monkey. Behav Brain Res 76:89-97.

Cavada C, Goldman-Rakic PS (1989) Posterior parietal cortex in rhesus monkey: II evidence for segregated corticocortical networks linking sensory and limbic areas with the frontal lobe. J Comp Neurol 287:422-445.

Colby CL, Duhamel JR (1991) Heterogeneity of extrastriate visual areas and multiple parietal areas in the macaque monkey. Neuropsychologia 29:517-537.

Colby CL, Gattass R, Olson CR, Gross CG (1988) Topogphical organization of cortical afferents to exstrastriate visual area PO in the macaque: a dual tracer study. J Comp Neurol 269:392-413.

Colby CL, Duhamel JR, Goldberg ME (1996) Visual, presaccadic, and cognitive activation of single neurons in monkey lateral intraparietal area. J Neurophysiol 76:2841-2852.

Cragg BG (1969) The topography of the afferent projections in the circumstriate visual cortex of the monkey studied by the Nauta method. Vision Res 9:733-747.

Desimone R, Gross CG (1979) Visual areas in the temporal cortex of the macaque. Brain Res 178:363-380. 
Desimone R, Ungerleider LG (1986) Multiple visual areas in the caudal superior temporal sulcus of the macaque. J Comp Neurol 248:164-189.

DeYoe EA, Van Essen DC (1985) Segregation of efferent connections and receptive field properties in visual area V2 of the macaque. Nature 317:58-61.

DeYoe EA, Felleman DJ, Van Essen DC, McClendon E (1994) Multiple processing streams in occipitotemporal visual cortex. Nature 371:151-154.

Distler C, Boussaoud D, Desimone R, Ungerleider LG (1993) Cortical connections of inferior temporal area TEO in macaque monkeys. J Comp Neurol 334:125-150.

Douglas RJ, Martin KAC (1991) A functional microcircuit for cat visual-cortex. J Physiol (Lond) 440:735-769.

Falchier A, Barone P, Kennedy H (2000) Eccentricity and cortical architecture. Eur J Neurosci [Suppl], in press.

Felleman DJ, Van Essen DC (1991) Distributed hierarchical processing in the primate cerebral cortex. Cereb Cortex 1:1-47.

Felleman DJ, Xiao Y, McClendon E (1997a) Modular organization of occipito-temporal pathways: cortical connections between visual area 4 and visual area 2 and posterior inferotemporal ventral area in macaque monkey. J Neurosci 17:3185-3200.

Felleman DJ, Burkhalter A, Van Essen DC (1997b) Cortical connections of areas V3 and VP of macaque monkey extrastriate visual cortex. J Comp Neurol 379:21-47.

Fitzpatrick KA, Imig TJ (1980) Auditory cortico-cortical connections in the owl monkey. J Comp Neurol 192:589-610.

Friedman DP (1983) Laminar patterns of termination of cortico-cortical afferents in the somatosensory system. Brain Res 273:147-151.

Gattass R, Gross CG, Sandell JH (1981) Visual topography of V2 in the macaque. J Comp Neurol 201:519-539.

Gattass R, Sousa APB, Gross CG (1988) Visuotopic organization and extend of V3 and V4 of the macaque. J Neurosci 8:1831-1845.

Gattass R, Sousa APB, Mishkin M, Ungerleider LG (1997) Cortical projections of area V2 in the macaque. Cereb Cortex 7:110-129.

Hardy H, Heimer L, Switzer R, Watkins D (1976) Simultaneous demonstration of horseradish peroxidase and acetylcholinesterase. Neurosci Lett 3:1-5.

Hilgetag CC, O'Neill MA, Young MP (1996a) Inderteminate organization of the visual system. Science 271:776-777.

Hilgetag CC, O'Neill MA, Young MP (1996b) Indeterminacy of the visual hierarchy: Top ten predictions. http://www.psychology.ncl.ac. uk/www/predictions.html.

Hof PR, Ungerleider LG, Webster MJ, Gattass R, Adams MM, Sailstad CA, Morrison JH (1996) Neurofilament protein is differentially distributed in subpopulations of corticocortical projection neurons in the macaque monkey visual pathways. J Comp Neurol 376:112-127.

Hof PR, Ungerleider LG, Adams MM, Webster MJ, Gatass R, Blumberg DM, Morrison JH (1997) Callosally projecting neurons in the macaque monkey V1/V2 border are enriched in nonphosphorylated neurofilament protein. Vis Neurosci 14:981-987.

Hubel D (1995) Eye, brain and vision. New York: Freeman and Co.

Hubel DH, Wiesel TN (1974) Uniformity of monkey striate cortex: a parallel relationship between field size, scatter, and magnification factor. J Comp Neurol 158:295-306.

Huerta MF, Krubitzer LA, Kaas JH (1987) Frontal eye field as defined by intracortical microstimulation in squirrel monkeys, owl monkeys, and macaque monkeys II. cortical connections. J Comp Neurol 265:332-361.

Hupé JM, James AC, Payne BR, Lomber SG, Girard P, Bullier J (1998) Cortical feedback improves discrimination between figure and background by V1, V2 and V3 neurons. Nature 394:784-787.

Ishai A, Sagi D (1995) Common mechanisms of visual imagery and perception. Science 268:1772-1774.

Iwai E, Mishkin M (1969) Further evidence on the locus of the visual area in the temporal lobe of the monkey. Exp Neurol 25:585-594.

Kaas JH (1996) Theories of visual cortex organization in primates: areas of the third level. In: Progress in brain research, Vol 112 (Norita M, Bando T, Stein B, eds), pp 213-221. Amsterdam: Elsevier.

Kaas JH, Hackett TA, Tramo MJ (1999) Auditory processing in primate cerebral cortex. Curr Opin Neurobiol 9:164-170.

Kaas JH, Lin CS (1977) Cortical projections in area 18 in owl monkeys. Vision Res 17:739-741.

Keizer K, Kuypers HGJM, Huisman AM, Dann O (1983) Diamidino yellow dihydrochloride (DY $2 \mathrm{HCl}$ ): a new fluorescent retrograde neu- ronal tracer, which migrates only very slowly out of the cell. Exp Brain Res 51:179-191.

Kennedy H, Bullier J (1985) A double-labelling investigation of the afferent connectivity of the afferent connectivity to cortical areas V1 and V2. J Neurosci 5:2815-2830.

Kennedy H, Bullier J, Dehay C (1989) Transient projections from STS to area 17 in the newborn monkey. Proc Natl Acad Sci USA 86:8093-8097.

Krubitzer LA, Kaas JH (1993) The dorsomedial visual area of owl monkeys: connections, myeloarchitecture, and homologies in other primates. J Comp Neurol 334:497-528.

Kuypers HGJM, Szwarcbart MK, Mishkin M, Rosvold HE (1965) Occipitotemporal corticocortical connections in the rhesus monkey. Exp Neurol 11:245-262.

Lagae L, Gulyas B, Raigel S, Orban GA (1989) Laminar analysis of motion information processing in macaque V5. Brain Res 496:361-367.

Lamme VA, Zipser K, Spekreijse H (1998) Figure-ground activity in primary visual cortex is suppressed by anesthesia. Proc Natl Acad Sci USA 95:3263-3268.

Livingstone MS, Hubel DH (1984) Anatomy and physiology of a color system in the primate visual cortex. J Neurosci 4:309-356.

Livingstone MS, Hubel DH (1987) Connections between layer 4b of area 17 and the thick cytochrome oxidase stripes of area 18 in the squirrel monkey. J Neurosci 7:3371-3377.

Lund JS, Lund RD, Hendrickson AE, Bunt AH, Fuchs AF (1975) The origin of efferent pathways from the primary visual cortex of the macaque monkey as shown by retrograde transport of horseradish peroxidase. J Comp Neurol 164:287-304.

Maguire WM, Baizer JS (1984) Visuotopic organization of the prelunate gyrus in rhesus monkey. J Neurosci 4:1690-1704.

Maunsell JHR, Van Essen DC (1983) The connections of the middle temporal visual area (MT) and their relationship to a cortical hierarchy in the macaque monkey. J Neurosci 3:2563-2586.

Meissirel C, Dehay C, Berland M, Kennedy H (1991) Segregation of callosal and association pathways during development in the visualcortex of the primate. J Neurosci 11:3297-3316.

Mesulam MM, Geula C (1994) Chemoarchitectonics of axonal and perikaryal acetylcholinesterase along information processing systems of human cerebral cortex. Brain Res Bull 33:137-153.

Miyashita Y (1995) How the brain creates imagery: projection to primary visual cortex. Science 268:1719-1720.

Morel A, Bullier J (1990) Anatomical segregation of two cortical visual pathways in the macaque monkey. Vis Neurosci 4:555-578.

Nakamura H, Gattass R, Desimone R, Ungerleider LG (1993) The modular organization of projections from area V1 and area V2 to area V4 and TEO in macaques. J Neurosci 13:3681-3691.

Nowak LG, Bullier J (1997) The timing of information transfer in the visual system. In: Cerebral cortex, Vol 12 (Rockland KS, eds), pp 205-241. New York: Plenum.

Nowak LG, Munk MHJ, Girard P, Bullier J (1995) Visual latencies in areas V1 and V2 of the macaque monkey. Vis Neurosci 12:371-384.

Perkel DJ, Bullier J, Kennedy H (1986) Topography of the afferent connectivity of area 17 in the macaque monkey: a double labelling study. J Comp Neurol 253:374-402.

Pons TP, Kaas JH (1986) Corticocortical connections of area 2 of somatosensory cortex in macaque monkey: a correlative anatomical and electrophysiological study. J Comp Neurol 248:313-335.

Raiguel S, Van Hulle MM, Xiao DK, Marcar VL, Orban GA (1995) Shape and spatial distribution of receptive fields and antagonistic motion surrounds in the middle temporal area (V5) of the macaque. Eur J Neurosci 7:2064-2082.

Rockland KS (1997) Element of cortical architecture. Hierarchy revisited. In: Cerebral cortex, Vol 12 (Rockland KS, Kaas JH, Peters A, eds), pp 243-293. New York: Plenum.

Rockland KS, Van Hoesen GWV (1994) Direct temporal-occipital feedback connection to striate cortex (V1) in the macaque monkey. Cereb Cortex 4:300-313.

Rockland KS, Pandya DN (1979) Laminar origins and terminations of cortical connections to the occipital lobe in the rhesus monkey. Brain Res 179:3-20.

Salin PA, Bullier J (1995) Corticocortical connections in the visual system: structure and function. Physiol Rev 75:107-154.

Scannell JW, Grant S, Payne BR, Baddeley R (2000) On variability in the density of corticocortical and thalamocortical connections. Philos Trans R Soc Lond B Biol Sci 355:21-35.

Schall JD, Morel A, King DJ, Bullier J (1995) Topography of visual 
cortex connections with frontal eye field in macaque: convergence and segregation of processing streams. J Neurosci 15:4464-4487.

Schmolesky MT, Wang Y, Hanes DP, Thompson KG, Leutgeb S, Schall JD, Leventhal AG (1998) Signal timing across the macaque visual system. J Neurophysiol 79:3272-3278.

Seltzer B, Pandya DN (1978) Afferent cortical connections and architectonics of the superior temporal sulcus and surrounding in the rhesus monkey. Brain Res 149:1-24.

Shipp S, Zeki S (1995) Segregation and convergence of specialized pathway in macaque monkey visual cortex. J Anat 187:547-562.

Silverman MS, Tootell RBH (1987) Modified technique for cytochrome oxidase histochemistry: increase staining intensity and compatibility with 2-desoxiglucose autoradiography. J Neurosci Methods 19:1-10.

Sousa AP, Pinon MC, Gattass R, Rosa MG (1991) Topographic organization of cortical input to striate cortex in the Cebus monkey: a fluorescent tracer study. J Comp Neurol 308:665-682.

Spatz WB (1977) Topographically organized reciprocal connections between areas 17 and MT (visual area of superior temporal sulcus) in the marmoset Callithrix jacchus. Exp Brain Res 27:559-572.

Spatz WB, Tigges J, Tigges M (1970) Subcortical projections, cortical associations, and some intrinsic interlaminar connections of the striate cortex in the squirrel monkey (saimiri). J Comp Neurol 140:155-174.

Stanton GB, Deng SY, Goldberg ME, McMullen NT (1989) Cytoarchitectural characteristic of the frontal eye fields in macaque monkeys. J Comp Neurol 282:415-427.

Stanton GB, Bruce CJ, Goldberg ME (1995) Topography of projections to posterior cortical areas from the macaque frontal eye field. J Comp Neurol 353:291-305.

Stepniewska I, Kaas JH (1996) Topographic patterns of V2 cortical connections in macaque monkeys. J Comp Neurol 371:129-152.

Suzuki WA (1996) The anatomy, physiology and functions of the perirhinal cortex. Curr Opin Neurobiol 6:179-186.

Suzuki WA, Amaral DG (1994a) Topographic organization of the reciprocal connections between the monkey entorhinal cortex and the perirhinal and parahippocampal cortices. J Neurosci 14:1856-1877.

Suzuki WA, Amaral DG (1994b) Perirhinal and parahippocampal cortices of the macaque monkey: cortical afferents. J Comp Neurol 350:497-533.

Tanaka M, Lindsley E, Lausmann S, Creutzfeldt OD (1990) Afferent connections of the prelunate visual association cortex (areas V4 and DP). Anat Embryol 181:19-30.

Tanigawa H, Fujita I, Kato M, Ojima H (1998) Distribution, morphology, and g-aminobutyric acid immunoreactivity of horizontally projecting neurons in the macaque inferior temporal cortex. J Comp Neurol 401:129-143.

Thompson KG, Hanes DP, Bichot NP, Schall JD (1996) Perceptual and motor processing stages identified in the activity of macaque frontal eye field neurons during visual search. J Neurophysiol 76:4040-4055.

Tigges J, Spatz WB, Tigges M (1973) Reciprocal point-to-point connections between parastriate and striate cortex in the squirrel monkey (saimiri). J Comp Neurol 148:481-490.

Tigges J, Tigges M, Anschel S, Cross NA, Letbetter WD, McBride RL (1981) Areal and laminar distribution of neurons interconnecting the central visual cortical areas $17,18,19$, and MT in squirrel monkey (saimiri). J Comp Neurol 202:539-560.

Tootell RBH, Silverman MS, De Valois RL, Jacobs GH (1983) Functional organization of the second cortical visual area of primate. Science 220:737-739.
Ungerleider LG, Desimone R (1986) Cortical connections of visual area MT in the macaque. J Comp Neurol 248:190-222.

Van Essen DC, Zeki S (1978) The topographic organization of rhesus monkey prestriate cortex. J Physiol (Lond) 277:193-226.

Van Essen DC, Maunsell JHR, Bixby JL (1981) The middle temporal visual area in the macaque: myeloarchitecture, connections, functional properties and topographic organization. J Comp Neurol 199:293-326.

Van Essen DC, Newsome WT, Maunsell JHR (1984) The visual field representation in striate cortex of the macaque monkey: asymmetries, anisotropies, and individual variability. Neuroscience 24:429-448.

Van Essen DC, Newsome WT, Maunsell JHR, Bixby JL (1986) The projections from striate cortex (V1) to areas $\mathrm{V} 2$ and $\mathrm{V} 3$ in the macaque monkey: asymmetries, areal boundaries, and patchy connections. J Comp Neurol 244:451-480.

Van Essen DC, Felleman DJ, DeYoe EA, Olavarria J, Knierim J (1990) Modular and hierarchical organization of extrastriate visual cortex in the macaque monkey. Cold Spring Harb Symp Quant Biol 55:679-696.

Vanduffel W, Payne BR, Lomber SG, Orban GA (1997) Functional impact of cerebral connections. Proc Natl Acad Sci USA 94:7617-7620.

Wall JT, Symonds LL, Kaas JH (1982) Cortical and subcortical projections of the middle temporal area (MT) and adjacent cortex in Galagos. J Comp Neurol 211:193-214.

Webster MJ, Ungerleider LG, Bachevalier J (1991) Connections of inferior temporal areas Te and Teo with medial temporal-lobe structures in infant and adult monkeys. J Neurosci 11:1095-1116.

Webster MJ, Bachevalier J, Ungerleider LG (1994) Connections of inferior temporal areas Teo and Te with parietal and frontal-cortex in macaque monkeys. Cereb Cortex 4:470-483.

Weller RE, Kaas JH (1985) Cortical projections of the dorsolateral visual area in owl monkeys: the prestriate relay to inferior temporal cortex. J Comp Neurol 234:35-59.

Weller RE, Wall JT, Kaas JH (1984) Cortical connections of the middle temporal visual area (MT) and the superior temporal cortex in owl monkeys. J Comp Neurol 228:81-104.

Wong-Riley M (1978) Reciprocal connections between striate and prestriate cortex in the squirrel monkey as demonstrated by combined peroxidase histochemistry and autoradiography. Brain Res 147:159-164.

Woodward JA, Bonett DG, Brecht M-L (1990) Introduction to linear models and experimental design. New York: Harcourt Brace Jovanovich.

Yoshioka T, Levitt JB, Lund JS (1992) Intrinsic lattice connections of macaque monkey visual cortical area V4. J Neurosci 12:2785-2802.

Young MP (1992) Objective analysis of the topological organization of the primate visual cortical system. Nature 358:152-155.

Yukie M, Iwai E (1985) Laminar origin of direct projection from cortex area V1 to V4 in the rhesus monkey. Brain Res 346:383-386.

Zeki S (1993) A vision of the brain. Oxford: Blackwell Scientific.

Zeki SM (1971) Cortical projections from two prestriate areas in the monkey. Brain Res 34:19-35.

Zeki SM (1974) Functional organization of a visual area in the posterior bank of the superior temporal sulcus in the rhesus monkey. J Physiol (Lond) 236:549-573.

Zeki SM (1978) Uniformity and diversity of structure and function in rhesus monkey prestriate visual cortex. J Physiol (Lond) 277:273-290.

Zipser K, Lamme VA, Schiller PH (1996) Contextual modulation in primary visual cortex. J Neurosci 16:7376-7389. 